\title{
Notas sobre informalidade, produtividade do trabalho e grau de utilização e seus impactos sobre o crescimento econômico no Brasil nos anos 2000
}

Some notes on informality, labour productivity and capacity utilization and its impacts over economic growth in Brazil in the 2000s

Claudio Roberto Amitrano

Instituto de Pesquisa Econômica

Gabriel Coelho Squeff

Instituto de Pesquisa Econômica

\begin{abstract}
This paper aims to discuss the implications of informality in Brazil by presenting new evidence on value added, occupations, and in labor productivity in the formal and informal sectors, disaggregated by economic activity. Moreover, we developed counterfactual exercises for these variables in order to assess the possible impacts of labor migration from non-formal sector to the formal sector as well as from changes in the rate of capacity utilization.
\end{abstract}

\section{Keywords}

labor productivity; informality; structural heterogeneity; economic growth.

JEL Codes J24; O17; L16; O47.

\section{Resumo}

Este artigo procura avançar na discussão sobre as implicações da informalidade no Brasil, apresentando novas evidências sobre a trajetória do valor adicionado, das ocupações e, sobretudo, da produtividade do trabalho nos setores formal e informal, desagregados por atividade econômica. Além disso, são desenvolvidos exercícios contrafactuais para a trajetória dessas variáveis com o intuito de avaliar os possíveis impactos da migração de trabalhadores dos setores não-formais para o setor formal e de modificações no grau de utilização da capacidade.

\section{Palavras-chave}

produtividade do trabalho; informalidade; heterogeneidade estrutural; crescimento econômico.

Códigos JEL J24; O17; L16; O 47. 


\section{Introdução}

Desde o trabalho seminal de Arthur Lewis, em 1954, mas, sobretudo, a partir do amplo debate promovido pela Cepal sobre heterogeneidade estrutural na América Latina, a literatura internacional tem se debatido sobre os efeitos deletérios que estruturas produtivas caracterizadas por expressiva desigualdade de produtividade inter e intrassetorial exercem sobre o crescimento econômico de longo prazo. Embora inicialmente voltado para os diferenciais de produtividade e salário entre setores tradicionais ou de subsistência (como por exemplo, a agropecuária dos nos 1950 e 1960) e modernos (como, por exemplo, os segmentos da manufatura na mesma época), o debate migrou do binômio moderno versus tradicional, à la Lewis, para outras dualidades, como a relação urbano/rural à la Harris e Todaro (1970), assim como para versões mais gerais acerca da heterogeneidade estrutural. Esses últimos extrapolam as análises dualistas, uma vez que a composição setorial da economia pode ser descrita de modo mais abrangente, a partir, por exemplo, das categorias de uso, da preponderância de fatores de produção ou da intensidade tecnológica nos processos produtivos.

Entretanto, desde o pioneiro estudo da OIT (1972) sobre as características do mercado de trabalho no Quênia, um dos aspectos que mais tem chamado a atenção dos analistas diz respeito à divisão da economia entre os segmentos formal e informal. Naquele estudo, o foco era o setor informal da economia urbana que se caracterizava como um fenômeno típico das chamadas economias subdesenvolvidas. É importante notar que a dualidade formal versus informal não representa uma mera substituição do binômio moderno versus tradicional, uma vez que o surgimento e a expansão do setor informal se configuram como um fenômeno moderno, decorrente do processo de urbanização (Cacciamali, 2007; Krein; Proni, 2010). A ideia central era que o desenvolvimento das relações mercantis modernas nesses países era incapaz de incorporar grande parte da população ao padrão de emprego capitalista, o que propiciou o aparecimento de novas estratégias de sobrevivência.

A repercussão desse debate na América Latina foi muito rápida. No final dos anos 60, a OIT já havia criado o Programa Regional del Emprego para a América Latina (PREALC), cujo intenso debate com a Comissão Econômica para a América Latina (Cepal) propiciou uma certa convergência entre a noção de heterogeneidade estrutural e a dualidade no mercado de traba- 
lho. Não por acaso, em seu estudo de 1978, o PREALC apresentava o setor informal urbano da região como uma manifestação do excedente de mão de obra, associado à heterogeneidade estrutural da economia. Enquanto o mercado formal determinava o nível de renda e emprego e introduzia o progresso técnico na economia, o setor informal, relacionado às atividades de baixa produtividade, funcionava como uma espécie de "colchão amortecedor" na fase recessiva, absorvendo mão de obra, e servia como "exército industrial de reserva" na fase expansiva, na medida em que fornecia a oferta de trabalho necessária ao setor formal nessa fase (Krein; Proni, 2010). Como bem observado por Tokman; Souza (1976; 1978), o setor informal reuniria as atividades não organizadas, seja do ponto de vista jurídico, seja do ponto de vista da típica relação capital-trabalho, em que o assalariamento perde sua centralidade. ${ }^{1}$

Para PREALC (1978), a heterogeneidade não se manifestava apenas entre setores, mas também internamente aos mesmos. No caso do setor informal, o estudo chamava a atenção para a existência de dois estratos, um superior e outro inferior, tese retomada recentemente por Günther; Launov (2006) em seu estudo sobre a Costa do Marfim, ainda que de um ponto de vista neoclássico, assim como Heintz; Poses (2008), cujo estudo sobre o caso sul-africano, orientado pelas teorias de segmentação no mercado de trabalho, encontrou evidências de barreiras à entrada, não só no setor formal, mas também entre os segmentos do setor informal. ${ }^{2}$

O debate brasileiro tem sido muito intenso e profícuo, ora criando abordagens novas e originais sobre esse tema, ora aplicando os desenvolvimentos teóricos produzidos na academia internacional, tanto aqueles oriundos das teorias institucionalistas de segmentação no mercado de trabalho à la Doeringer; Piore (1981), quanto aqueles de orientação mais neoclássica, baseados no conceito de assimetria de informações à la Shapiro e Stiglitz (1984), Stiglitz (1985) e Akerlof e Yellen (1986), ou ainda aqueles vinculados à teoria do capital humano, como bem observado por Fields (2009).

No primeiro caso, merece destaque o trabalho de Cacciamali (1983), para quem a característica central do setor informal é sua inserção intersticial subordinada, cuja ideia central está relacionada à hipótese de que parte das demandas da sociedade por bens e serviços é atendida por atividades

1 Veja a esse respeito também, Cacciamalli (1983; 2007).

2 Retomaremos esse ponto adiante. 
cuja lucratividade não é suficiente para atrair as firmas tipicamente capitalistas (Hirata; Machado, 2008).

No segundo caso, destacam-se particularmente os estudos de Barros, Mello e Pero (1993), Ramos (2002), Soares (2004b), entre outros, cujo objetivo é não só descrever as características principais do setor informal, mas também avaliar em que medida a existência desse tipo de ocupação é resultado de barreiras à entrada no segmento formal, à là teorias de segmentação ou da decisão dos trabalhadores que, ao maximizarem sua função utilidade, encontram maiores remunerações e/ou benefícios não-pecuniários melhores e/ou em maior quantidade no setor informal, tal como estabelecido pelos chamado modelo competitivo da tradição neoclássica.

De fato, Ulyssea (2005) ao fazer uma extensa revisão da literatura sobre o mercado de trabalho informal no Brasil constata o predomínio de artigos devotados à caracterização deste mercado e dos trabalhadores informais, notadamente no que se refere à educação, à rotatividade, à probabilidade de formalização, ao diferencial salarial, à existência de segmentação, entre outros. Cabe notar que alguns desses estudos encontraram evidências de que a existência e o tamanho do setor informal no Brasil dependem tanto das barreiras à entrada como da decisão dos trabalhadores. A taxonomia de Cimoli et al. (2006) indica que a forma de inserção depende do grupo de trabalhadores considerado, haja vista a enorme heterogeneidade do setor informal. Essas evidências têm sido corroboradas pela literatura internacional, como evidenciam os estudos de Günther; Launov (2006) e Heintz; Poses (2008) citados anteriormente.

Para Ulyssea, o setor informal deve ser entendido como "um 'elo' importante entre os fatores que determinam a oferta e a demanda por trabalho (instituições, qualificação da mão-de-obra e ambiente macroeconômico) e os resultados relevantes do mercado de trabalho (emprego, distribuição e nível dos rendimentos do trabalho, produtividade e crescimento econômico)." (2005, p. 18).

Evidentemente, essa breve resenha não esgota o imenso debate sobre o setor informal, sobretudo após a mudança de perspectiva proposta pela OIT. A introdução do conceito de economia informal e trabalho decente lançaram um novo olhar para o fenômeno da informalidade (OIT, 2002; Cacciamali, 2007; Hirata; Machado, 2008). Todavia, o sumário apresentado é suficiente para esclarecer algumas questões centrais do debate e revelar a predominância de estudos centrados no mercado de trabalho. 
Com efeito, abordagens voltadas para a discussão das atividades produtivas e seus impactos sobre o crescimento econômico são relativamente escassas. Do ponto de vista teórico, encontram-se entre as exceções os trabalhos de Cimoli et al. (2006), Rada (2007) e Ocampo, Rada e Taylor (2009). Mas, mesmo assim, apenas Cimoli et al. (2006) tratam especificamente da dualidade formal versus informal. Em seu estudo, os autores elaboram um modelo dual no qual a dinâmica do setor formal é dada por um regime de demanda e por um regime de produtividade, em linha com a perspectiva kaldoriana, e o setor informal assume um papel residual expresso, entre outros, pelo fato de a produtividade desta última ter sido definida como uma função daquela verificada para o setor formal. A solução do modelo indica que a estrutura produtiva restringe a possibilidade de uma estratégia de crescimento liderada pelas exportações e que a fragilidade estrutural do setor informal reduz o crescimento econômico. ${ }^{3}$

No campo da empiria, novamente, a miríade de estudos sobre informalidade no mercado de trabalho não encontra paralelo nos estudos que discutem esse fenômeno sob a ótica do setor de produção. Concorre para isto, sobretudo, a ausência de dados oficiais sobre a estrutura produtiva nos setores formal e informal, notadamente com relação à produção e ao emprego.

Uma das exceções é o trabalho de Kupfer e Rocha (2005) que, em linha com a abordagem estruturalista, discute a heterogeneidade estrutural brasileira entre 1996 e 2001 do ponto de vista intrassetorial a partir dos dados da Pesquisa Industrial Anual - PIA do IBGE. Neste estudo, foi encontrada uma correlação negativa entre o crescimento da produtividade das empresas com mais de 29 empregados (proxy do setor formal) e o aumento do emprego nas empresas com até quatro empregados (aproximação do setor informal). Ademais, os autores também encontram evidências de aumento da heterogeneidade estrutural no setor formal da indústria brasileira. Outra exceção é o trabalho de Hallak Neto et al. $(2012)^{4}$ que se debruça intensamente sobre este fenômeno sob a ótica do setor de produção.

O presente artigo contribui para a discussão aplicada ao tema das implicações da informalidade no Brasil ao apresentar dados novos sobre a evolução do valor adicionado, das ocupações e, sobretudo, da produtividade ção de atividade econômica para o ano de 2007. Em versão anterior (Hallak Neto et al. 2009) os autores realizam exercício análogo para 2006. 
do trabalho nos setores formal e informal, desagregados por atividade econômica. Adicionalmente, desenvolvemos exercícios contrafactuais para a trajetória dessas variáveis com o intuito de avaliar os possíveis impactos da migração de trabalhadores dos setores não-formais para o setor formal. Isto porque, ao analisarmos os impactos da segmentação da economia entre setores formal e informal, além de captarmos um fato estilizado sobejamente conhecido das economias latino-americanas, essa classificação permite identificar trajetórias tecnológicas distintas que se caracterizam por significativos diferenciais de produtividade.

O artigo está dividido em 5 partes, além desta introdução. Na primeira são apresentados o conceito de informalidade e a metodologia de cálculo da produtividade do trabalho segundo o setor de produção e atividade econômica. Em seguida, são apresentados os principais resultados encontrados nos anos 2000. Na terceira seção são realizados exercícios de simulação para a dinâmica do valor adicionado com base na migração de trabalhadores para o setor formal, de modo a se obter cenários alternativos para a produtividade agregada e segundo atividade econômica. Na quarta seção, discutimos o impacto das alterações no grau de utilização da capacidade na evolução da produtividade e do valor adicionado na indústria de transformação. Por fim, como de praxe, na última seção, são tecidas as considerações finais.

\section{Metodologia de estimação do valor adicionado, ocupações e produtividade do trabalho nos setores formal, informal e outras unidades familiares}

O Sistema de Contas Nacionais do Brasil - referência 2000 (doravante SCN 2000), em consonância com as recomendações do System of National Accounts da Organização das Nações Unidas de 1993 e 2008, determina que emprego informal se refere à qualificação dos postos de trabalho, ao passo que setor informal está relacionado à estrutura produtiva. As ocupações com vínculo formal consistem nos assalariados com carteira de trabalho assinada, os funcionários públicos estatutários, os militares e os empregadores (sócios e proprietários) de empresas formalmente constituídas. Já as ocupações sem vínculo contemplam os assalariados sem carteira de trabalho assinada e trabalhadores autônomos, sendo este último ainda 
desmembrado em conta própria, trabalhadores não remunerados e empregadores informais.

Já sob ótica da estrutura produtiva, o SCN 2000 estabelece que o setor informal da economia é um subconjunto do setor institucional "Famílias" no qual estão as unidades produtivas não-agrícolas, sem uma clara divisão entre capital e trabalho enquanto fatores de produção, cuja produção é destinada prioritariamente ao mercado. O restante de "Famílias" - relacionado à agricultura mercantil ou para autoconsumo, ao aluguel imputado e efetivo e às famílias que empregam trabalhadores domésticos remunerados - não pertence ao setor formal, mas sim a um terceiro grupo denominado "outras unidades familiares" (IBGE, p. 52, 2008c; Hallak Neto et al., 2012, p. 100-101).

Desse modo, tanto o emprego formal quanto o informal podem estar presentes nos diferentes setores de produção. Ou seja, pode haver emprego formal numa atividade produtiva do setor informal e emprego informal numa atividade formal (Hussmanns, 2004; IBGE, 2008a; IBGE 2008b). $O$ presente trabalho discute exclusivamente a informalidade enquanto setor de produção, de modo que, doravante, qualquer referência à informalidade, ao setor informal ou, ainda, à economia informal ${ }^{5}$ diz respeito à produção e/ou ao valor adicionado gerado no setor de produção informal. Igualmente, neste artigo as ocupações informais são aquelas alocadas nas unidades produtivas informais, sem distinção do tipo de vínculo ocupacional.

Este artigo cobre o período 2000 a 2009 e utiliza os dados anuais do Sistema de Contas Nacionais do Brasil - referência 2000 do IBGE. ${ }^{6}$ Foram utilizadas apenas as tabelas sinóticas 9, 13 e 21, sendo que para esta última foi necessária uma tabulação especial. Na tabela sinótica 9 está reportado o valor adicionado bruto (VA) a preços correntes e a preços constantes do ano anterior no nível 56. A tabela sinótica 13 apresenta o total de ocupações também no nível 56. Já na tabela sinótica 21 está apresentado o VA a preços correntes e o total de ocupações por setor institucional e segundo

5 Desde 2002 a OIT recomenda a utilização de "economia informal" ao invés de "setor informal" na medida em que os trabalhadores e empreendimentos informais não pertencem unicamente a uma atividade econômica (OIT, 2002). Como neste trabalho é feita a distinção por atividade econômica dentro dos setores formal e informal, serão utilizados os termos "economia informal" e "setor informal" indistintamente.

6 Este trabalho foi concluído antes da divulgação da nova série do Sistema de Contas Nacionais (SCN) - referência 2010. Além disso, como foram utilizadas tabulações especiais do IBGE que ainda não estão disponíveis, não foi possível refazer os cálculos a partir da nova metodologia. 
12 atividades econômicas. A tabulação especial desta tabela consistiu na inserção do total de ocupações, uma vez que a tabela sinótica 21 disponível no sítio do IBGE na internet apresenta apenas as informações de produção, consumo intermediário e valor adicionado.?

Em conformidade com a metodologia do IBGE, a construção das séries de VA, ocupações e produtividade do trabalho requereu inicialmente que os dados fossem agrupados segundo o setor de produção em "Formal", "Informal" e "Outras unidades familiares", à semelhança do empreendido por Hallak Neto et al. (2012). Dada a disponibilidade de informações, a desagregação por atividade econômica só pôde ser feita no nível 12. Sendo assim, as 12 atividades econômicas do setor "Formal" foram obtidas pelo somatório de cada uma dessas respectivas atividades nos setores institucionais "Empresas não-financeiras", "Empresas financeiras", "Administração pública" e "Instituições sem fins de lucro a serviço das famílias".

Conforme destacado anteriormente, a informalidade da economia é um subconjunto do setor institucional "Famílias" no qual estão as unidades produtivas não-agrícolas, ao passo que o subconjunto restante pertence ao setor de produção "Outras unidades familiares" e está relacionado à agricultura mercantil ou para autoconsumo, ao aluguel imputado e efetivo e às famílias que empregam trabalhadores domésticos remunerados. Assim, as 12 atividades do setor institucional "Famílias" foram distribuídas da seguinte forma. "Outras unidades familiares" possuem três atividades: "Agropecuária", "Atividades imobiliárias e aluguéis" e "Serviços domésticos", sendo esta última disponível somente no nível 56 e, portanto, retirada da tabela sinótica 9 (no caso do VA) e da tabela sinótica 13 (no caso das ocupações).

A totalidade de "Atividades imobiliárias e aluguéis" do setor institucional "Famílias" foi incluída em "Outras unidades familiares" em decorrência de não estarem disponíveis desagregações da produção desta atividade por setor institucional. ${ }^{8}$ Entretanto, como a maior parte da produção desta atividade é não-mercantil, expressa pelo produto "aluguel imputado", cujo valor não diz respeito à atividade de produção informal

7 autor agradece à equipe da Coordenação de Contas Nacionais - CONAC do IBGE pelo envio desta tabela.

8 Hallak Neto et al. (2012) dispuseram destas informações em seu trabalho. Por questões de sigilo, esses dados não estão disponíveis no sítio do IBGE e não puderam ser enviados sob a forma de tabulação especial aos autores do presente artigo. 
das "Famílias", a adoção da hipótese de que todo o VA desta atividade pertence a "Outras unidades familiares" não implica numa aproximação muito imprecisa da realidade.

Concorreu para a adoção desta hipótese o fato de que "a estimação do valor do aluguel imputado é baseada em um modelo estatístico que usa as características dos imóveis residenciais efetivamente alugados para estimar o efeito de cada uma delas sobre o valor do aluguel. Com essas informações, o modelo imputa valores de aluguel para os imóveis próprios" (IBGE, 2008c). Adicionalmente, com base nas TRUs no nível 56, temos que entre 2000 e 2009 este produto respondeu por aproximadamente $70 \%$ da produção de "Atividades imobiliárias e aluguéis".

Por exclusão, o setor "Informal" é composto por oito atividades econômicas, das quais sete - "Indústria extrativa", "Indústria de transformação", "Construção civil", "Comércio", "Transporte, armazenagem e correio", "Serviços de informação" e "Intermediação financeira, seguros e previdência complementar e serviços relacionados" - advêm diretamente do setor institucional "Famílias". A oitava atividade, denominada "Outros serviços ajustado", foi obtida a partir da subtração do VA e das ocupações de "Serviços domésticos" do total de "Outros serviços" verificado no setor institucional "Famílias". ${ }^{9}$ Logo, a dedução desta última atividade do total de "Outros serviços" requereu uma nova taxonomia.

Deste modo, obteve-se 23 unidades de análise no presente trabalho, sendo 12 pertencentes ao setor "Formal", oito ao setor "Informal" e três ao setor de produção "Outras unidades familiares". Não obstante, tem-se 13 atividades econômicas, pois, conforme mencionado, foi necessário criar a atividade "Outros serviços ajustado".

A avaliação da variação de volume (crescimento real) do VA e da produtividade do trabalho de uma determinada atividade requer a eliminação do efeito preço das séries em valor nominal. O SCN 2000, em consonância com as recomendações do System of National Accounts (SNA) de 1993 e 2008, calcula os índices de preço e de volume com relação ao ano anterior, caracterizando um sistema de base móvel. No cálculo do VA utiliza-se o chamado método de dupla deflação, por meio do qual a variação de preços

9 A atividade "Outros serviços" no nível 12 corresponde às seguintes atividades no nível 56: "Serviços de manutenção e reparação", "Serviços de alojamento e alimentação", "Serviços prestados às empresas", "Educação mercantil", "Saúde mercantil", "Serviços prestados às famílias e associativas" e "Serviços domésticos". 
do VA é calculada implicitamente após a deflação da produção e do consumo intermediário por índices específicos. Para a variação de preços são utilizados índices de Paasche, ao passo que para a variação de volume são utilizados índices de Laspeyres. Então, o cálculo do VA no ano t a preços de t-1 pode ser feito de duas maneiras equivalentes: pela multiplicação do VA no ano t-1 a preços correntes pelo índice de Laspeyres de quantidade entre $t-1$ e t ou pela divisão do VA no ano $t$ a preços correntes pelo índice de Paasche de preço entre t- 1 e t. Assim, para transformar dados a preços correntes para preços constantes de um determinado ano-base basta encadear os índices de Paasche ou de Laspeyres.

Desta feita, os dados da tabela sinótica 9 foram agrupados nestas 13 atividades econômicas, resultando numa tabela com VA a preços correntes e preços do ano anterior entre 2000 e 2009. A partir de tais informações foram calculadas as variações de preços entre os anos 2001 e 2009, de modo que se obteve uma tabela com as variações de preços do VA segundo 13 atividades econômicas. A próxima etapa consistiu em deflacionar o VA corrente da tabela 21 pelas correspondentes variações de preços acima mencionadas, devidamente encadeadas tendo como ano-base 2000. Implicitamente, portanto, assumiu-se que a inflação/deflação do VA de uma determinada atividade econômica independe do setor institucional. Reconhece-se de antemão que, a priori, não há razão para que o índice de preços da atividade de um determinado setor institucional, por exemplo, "Indústria extrativa" de "Famílias", seja igual àquele verificado para esta mesma atividade em outro setor institucional, por exemplo, "Indústria extrativa" de "Empresas não-financeiras". Entretanto, inexistem dados de variação de preços discriminados por setor institucional para nenhum nível de agregação por atividade econômica - as únicas CEI disponíveis estão no nível 12 apenas a preços correntes, de modo que, novamente, o método aplicado foi o único disponível. Assim, construiu-se uma série de VA a preços constantes de 2000 para as 23 unidades de análise entre 2000 e 2009. ${ }^{10}$

Neste sentido, é mister ressaltar que como as contas nacionais brasileiras são do tipo base móvel, a passagem dos dados de VA para uma base fixa implica a chamada perda de aditividade: a soma dos VAs desagregados

10 Em 2003 e 2004, havia R\$ 3 milhões de VA da atividade "Ind. Transformação" no setor institucional "Empresas financeiras". Como inexistem ocupações na referida atividade econômica / setor institucional, optamos por adicionar estes R \$ 3 milhões de VA ao setor institucional "Empresas não-financeiras". 
a preços constantes não é igual ao VA agregado a preços constantes (IBGE, 2008c; Feijó e Ramos, 2008). Optamos por manter os dados a preços constantes com o referido problema de aditividade, uma vez que as alternativas possíveis a este procedimento - ajustar as séries desagregadas ao total agregado ou tornar o total agregado igual à soma das partes desagregadas - implicam na modificação dos dados originais do IBGE.

Por fim, é importante ressaltar que, tal como definido no presente trabalho, é muito complicado discutir produtividade do trabalho em algumas atividades econômicas. Uma parcela considerável da produção de "Intermediação financeira, seguros e previdência complementar e serviços relacionados" são os chamados serviços de intermediação financeira indiretamente medidos - SIFIM. O SIFIM corresponde "ao total de rendimentos de propriedade a receber pelos intermediários financeiros líquidos dos juros totais a pagar, excluindo o valor de qualquer rendimento de propriedade a receber de investimentos de fundos próprios" e é calculado "pelo diferencial dos juros recebidos e dos juros pagos, com base na aplicação nas contas ativas e passivas geradoras de SIFIM, de taxas médias de juros selecionadas de acordo com a transação e (...) a Selic - Sistema Especial de Liquidação e Custódia -, média do ano" (IBGE, 2010).

Igualmente complicado é discutir a produtividade em "Atividades imobiliárias e aluguéis" e "Serviços domésticos", de "Outras unidades familiares", e "Administração, saúde e educação públicas e seguridade social" do setor "Formal", pois são atividades praticamente não-mercantis. Para o primeiro, concorre o já mencionado aluguel imputado, ao passo que para os demais se constata que o valor adicionado destas atividades é praticamente igual aos salários, de tal modo que políticas de valorização do salário mínimo e/ou da remuneração de servidores públicos podem culminar no "aumento" de produtividade nessas atividades. ${ }^{11}$

Adicionalmente, vale destacar que a produtividade em "Agropecuária", de "Outras unidades familiares", também deve ser avaliada com muita cautela. Esta atividade também contempla a produção para autoconsumo, de tal forma que, como não estão disponíveis dados adequados para sepa-

11 Os serviços de educação pública, saúde pública e administração pública são estimados separadamente por meio das classificações econômica, institucional e funcional das contas de vários órgãos da administração pública direta e indireta (IBGE, p. 58, 2008c). Nesse sentido, cumpre ressaltar que a educação mercantil e a saúde mercantil não fazem parte de "Administração, saúde e educação públicas e seguridade social"; tais atividades fazem parte da atividade "Outros serviços". 
rar os dois componentes, é possível que a nossa estimativa de produtividade do trabalho em "Agropecuária", de "Outras unidades familiares", seja pouco precisa.

A despeito destas ressalvas, optamos por apresentar nossos resultados considerando todas as atividades econômicas por dois motivos. Primeiro, por mais complicada que seja a compreensão analítica das imputações realizadas pelo IBGE para fins de avaliação da produtividade do trabalho, as atividades financeiras e de aluguéis, os serviços domésticos e os serviços públicos contribuíram, em maior ou menor medida, para o valor adicionado total. Adicionalmente, a grande maioria dos trabalhos que discute produtividade do trabalho agregada no Brasil não expurga as referidas atividades econômicas, de modo que apresentar os resultados considerando todas as atividades é útil para fins de comparação com outras pesquisas.

\section{Resultados}

Como mostra a tabela 1, entre 2000 e 2009, o setor de produção formal aumentou sua participação no valor adicionado total de $72,8 \%$ para $80 \%$, ao passo que em termos de ocupações este aumento foi ligeiramente menor, de $47,5 \%$ para $54 \%$. Assim, a constatação de que pouco mais da metade das ocupações estavam vinculadas aos empreendimentos formais no final da década passada indica a existência de condições precárias na estrutura de produção brasileira de maneira geral. Entre as atividades econômicas formais que aumentaram sua participação no total destaca-se "Comércio" que isoladamente respondeu por quase a metade do crescimento do VA e por 1/3 do crescimento das ocupações do setor formal. São dignos de nota ainda o aumento da participação da "Administração pública" (termos de VA) e de "Outros serviços" (ocupações).

A contrapartida do aumento da formalidade foi uma redução muito próxima nos outros dois setores de produção. No caso do setor informal, a queda em termos de VA foi de 4 pontos percentuais (p.p.), enquanto as ocupações caíram 2,9 p.p., com destaque para as atividades "Comércio" e "Outros serviços". Isso implica, portanto, que a maior parte do processo de formalização ocorreu dentro das atividades econômicas - no caso, unidades produtivas informais pertencentes ao "Comércio" e aos "Outros serviços" passaram a ser formais sem mudança de atividade econômica. 
Já no setor "Outras unidades familiares" a queda em ambas as variáveis foi semelhante e em torno de 3 p.p. Esse desempenho é quase que integralmente explicado por "Atividades imobiliárias" no caso do VA, de 10,8\% para 7,5\%, e por "Agropecuária", no caso das ocupações, de 17,1\% para 13,1\%. Não obstante, a atividade "Serviços domésticos" foi na contramão de todas as atividades não-formais, uma vez que houve aumento de sua participação no VA e nas ocupações totais.

A tabela 1 também mostra as taxas de variação anuais médias do valor adicionado e das ocupações nos anos 2000. No que concerne aos resultados agregados, destaca-se que o crescimento do valor adicionado total de $3,1 \%$ a.a. decorreu da dinâmica dos setores formal (+3,8\%a.a.) e outras unidades familiares ( $+3,1 \%$ a.a.), uma vez que nas atividades informais como um todo houve redução no VA de $-1,4 \%$ a.a.

As duas atividades que apresentaram as maiores taxas de crescimento do VA pertencem ao setor formal: "Atividades imobiliárias e aluguéis", com surpreendentes $14,4 \%$ a.a., e "Intermediação financeira, seguros e previdência complementar e serviços relacionados", com 5,7\% a.a. Entretanto, é necessário ter cautela com esses números, assim como aqueles relacionados à produtividade do trabalho, uma vez que as atividades possuem especificidades de estimação que devem ser levadas em conta, conforme mencionado na metodologia. Desse modo, convém destacar as outras duas atividades que mais cresceram em termos de VA, quais sejam, "Comércio" ( $+5,3 \%$ a.a.) e "Serviços de informação" (+5,1\% a.a.).

O desempenho dos serviços de informação é interessante na medida em que até no setor informal houve variação positiva do VA (+2,6\% a.a.), ao contrário de todas as demais atividades informais. As maiores quedas ocorreram na indústria extrativa (-2,6\% a.a.) e, sobretudo, em "Comércio" (-3,3\% a.a.), o que reforça o argumento de que o grosso do processo de formalização ocorreu sem mudança de atividade econômica.

Já em termos de ocupações, houve crescimento em todos os setores da produção, incluindo um ligeiro crescimento no setor informal de 0,4\% a.a., resultando numa taxa de variação anual média das ocupações totais de 2,3\% a.a. Sob a ótica desagregada, verifica-se um forte crescimento das ocupações formais na construção civil ( $+6,1 \%$ a.a.), no comércio $(+4,9 \%$ a.a.) e em outros serviços $(4,9 \%$ a.a.), o que sugere uma baixa qualificação dos postos de emprego gerados nos anos 2000. Entre as atividades com queda na taxa de crescimento, destacam-se "Indústria extrativa", do setor informal, 


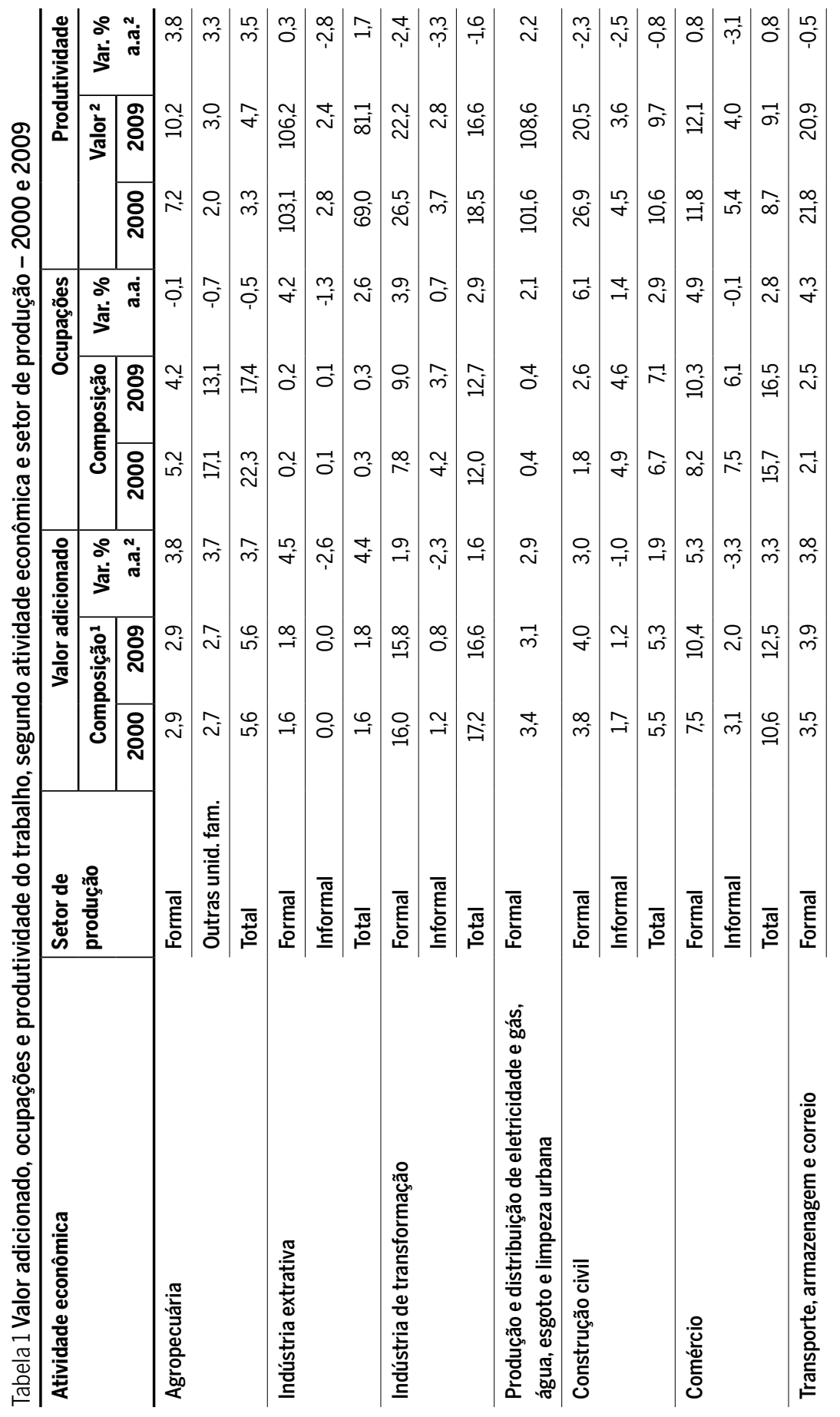




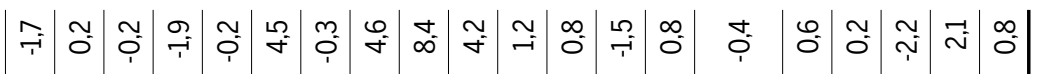

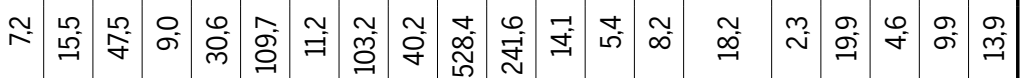

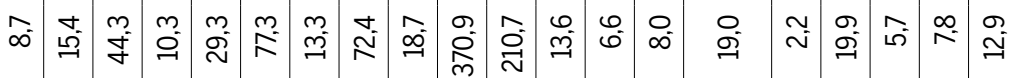

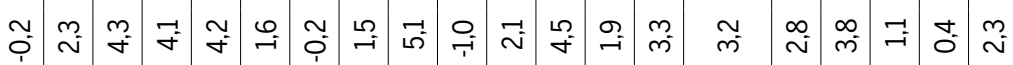

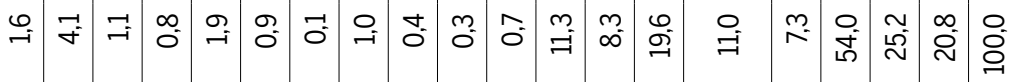

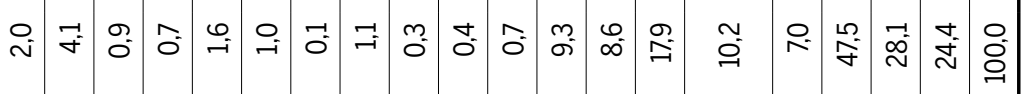

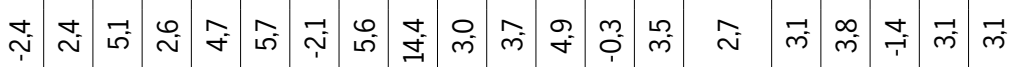

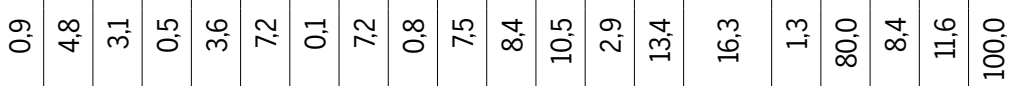

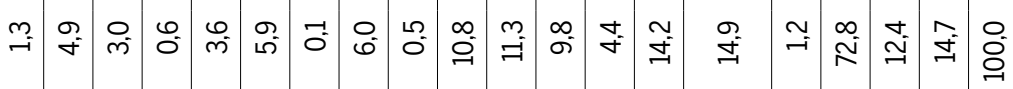

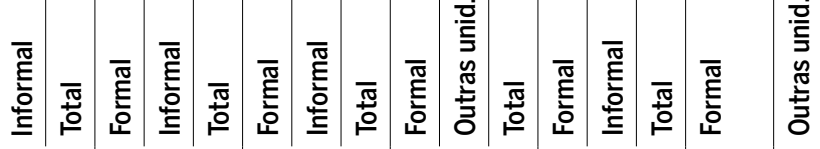

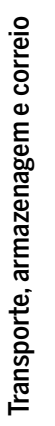

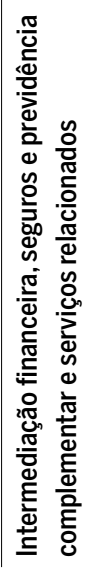

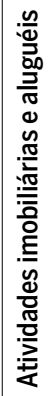

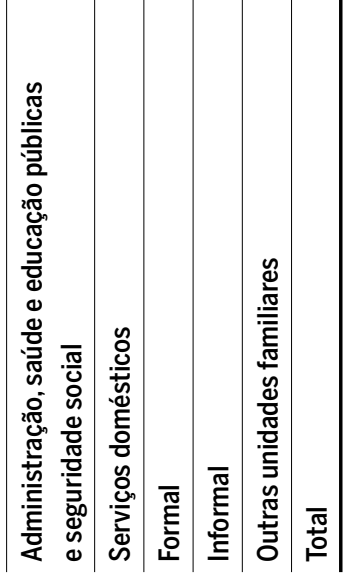

$$
\begin{aligned}
& \text { กั } \\
& 8 \\
& \frac{\sqrt{0}}{\frac{1}{ \pm}}
\end{aligned}
$$

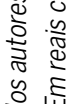

$$
\begin{aligned}
& \text { זొ্ } \\
& \text { ô }
\end{aligned}
$$

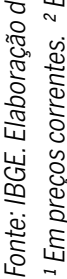


e "Agropecuária" e "Atividades imobiliárias e aluguéis" de outras unidades familiares. Como um todo, as ocupações neste último setor cresceram 3,1\% a.a., com destaque para "Serviços domésticos", uma vez que esta foi a única atividade de outras unidades familiares com crescimento nas ocupações, sendo a taxa apresentada ( $2,8 \%$ a.a.) maior que a verificada para o total.

Finalmente, a tabela 1 mostra a evolução da produtividade do trabalho. O primeiro ponto a ser destacado diz respeito à enorme disparidade entre os níveis de produtividade. Por exemplo, a produtividade do trabalho total é da ordem de $\mathrm{R} \$ 13$ mil, ao passo que nos setores formal e informal obtivemos R \$ 20 mil e R \$ 5 mil, respectivamente. Adicionalmente, "Indústria extrativa" formal e "Produção e distribuição de eletricidade e gás, água, esgoto e limpeza urbana" são atividades cuja produtividade é aproximadamente oito vezes superior à produtividade média da economia, ao passo que o contrário foi verificado para todas as atividades informais. Ademais, vale a pena destacar que apenas duas atividades formais - "Agropecuária" e "Comércio" - tiveram níveis de produtividade inferiores ao total.

O crescimento da produtividade agregada de $0,8 \%$ a.a. decorreu, sobretudo, da dinâmica de outras unidades familiares, uma vez que no setor formal como um todo a produtividade permaneceu estagnada e houve queda de $2,4 \%$ a.a. no setor informal. ${ }^{12}$ Complementarmente, na maioria das atividades formais houve aumento da produtividade do trabalho, com destaque para a Agropecuária (+3,9\% a.a.); as mais relevantes exceções foram "Indústria de transformação" (-2,0\% a.a.) e "Construção civil" (-3,0\% a.a.). Já no setor informal, todas as atividades econômicas apresentaram queda de produtividade, sendo os casos mais proeminentes "Comércio" (-3,3\% a.a.) e "Indústria de transformação" (-3,0\% a.a.). Evidencia-se, portanto, a manutenção da heterogeneidade estrutural brasileira, tanto nos níveis quanto nas taxas de variação da produtividade.

12 Novamente, em função de especificidades de mensuração do valor adicionado, é necessária muita cautela ao avaliar a produtividade do trabalho das atividades "Intermediação financeira, seguros e previdência complementar e serviços relacionados", "Atividades imobiliárias e aluguéis", "Serviços domésticos" e "Administração, saúde e educação públicas e seguridade social", assim como do setor outras unidades familiares. O nível e taxa de crescimento dessa variável em "Atividades imobiliárias e aluguéis" ilustram claramente essa peculiaridade. Todavia, optamos por manter todas as atividades e setores na análise, pois o objetivo do presente artigo é discutir a evolução da produtividade do trabalho total à luz da dinâmica verificada em seus componentes (por setor de produção e por atividade econômica), assim como a partir da realização de cenários alternativos do desempenho desses componentes nos anos 2000 (seção 3). 


\section{Contrafactuais e exercícios de simulação para a economia brasileira}

A seção 2 mostrou que para todas as atividades cuja produção pode ser dividida entre os segmentos formal, informal e outras unidades familiares, os setores formais de cada atividade apresentaram produtividade em valor absoluto superior a de qualquer outro setor.

Uma pergunta que decorre diretamente dessa constatação é o que teria acontecido com a economia brasileira se todo o emprego criado ao longo do período analisado tivesse sido gerado no setor formal? Dados os diferenciais de produtividade relatados, esperar-se-ia que a taxa de crescimento entre 2000 e 2009 fosse superior à verificada historicamente.

Para responder à tal pergunta, a presente seção foi dividida em duas partes. Na primeira, são apresentados os exercícios contrafactuais de migração das ocupações dos setores não-formais para o setor formal. Em seguida, os resultados desses exercícios são apresentados e comparados com o desempenho histórico da produtividade do trabalho nos anos 2000.

\subsection{Descrição dos exercícios contrafactuais}

Com base na identidade do produto, é possível demonstrar analiticamente e simular empiricamente os impactos de uma hipotética migração de trabalhadores dos setores informal e de outras unidades familiares para o setor formal. É importante esclarecer de antemão que o exercício contrafactual proposto se refere a efeitos sincrônicos sobre o valor adicionado, oriundos de elementos constitutivos apenas da oferta de bens e serviços, sendo, portanto, incapaz de captar os efeitos dinâmicos e as interações com a demanda da economia. No entanto, a despeito dessas limitações, e por que não dizer que por conta delas, o exercício se configura como um poderoso indicador dos impactos do processo de formalização das atividades econômicas ao simular os menores efeitos positivos possíveis da formalização da economia.

O primeiro exercício é bastante intuitivo e começa apenas explicitando uma identidade possível para o produto agregado da economia. Formalmente, tem-se que o VA no ano t nada mais é do que a produtividade do trabalho multiplicada pelo estoque de ocupações, ambos em t. Se acrescentarmos a essa descrição a segmentação da economia entre setores for- 
mais, informais e outras unidades familiares, então teremos que o PIB em $t$ corresponderá à soma das produtividades setoriais multiplicadas por seus respectivos estoques de ocupações, conforme as identidades a seguir.

$Y^{t}=Y_{F}^{t}+Y_{I}^{t}+Y_{O}^{t}$

$N^{t}=N_{F}^{t}+N_{I}^{t}+N_{O}^{t}$

$\alpha^{t}=\frac{Y^{t}}{N^{t}} ; \alpha_{F}^{t}=\frac{Y_{F}^{t}}{N_{F}^{t}} ; \alpha_{I}^{t}=\frac{Y_{I}^{t}}{N_{I}^{t}} ; \alpha_{O}^{t}=\frac{Y_{O}^{t}}{N_{O}^{t}}$

$Y^{t}=\alpha^{t} \cdot N^{t}$

$Y^{t}=\alpha_{F}^{t} \cdot N_{F}^{t}+\alpha_{I}^{t} \cdot N_{I}^{t}+\alpha_{O}^{t} \cdot N_{O}^{t}$

Generalizando: $Y^{t}=\sum_{i=1}^{m} \alpha_{i}^{t} \cdot N_{i}^{t}$

em que $Y^{t}$ correspo nde ao valor adicionado agregado total da economia no ano t, $Y_{F}^{t}$ é o valor adicionado do setor formal, $Y_{I}^{t}$ é o valor adicionado do setor informal e $Y_{O}^{t}$ representa o valor adicionado das outras unidades familiares. De maneira análoga, $N^{t}$ corresponde ao estoque total de ocupações na economia no ano t, $N_{F}^{t}$ é o estoque de ocupações do setor formal, $N_{I}^{t}$ é o estoque de ocupações do setor informal e $N_{O}^{t}$ representa o estoque de ocupações das outras unidades familiares. Por sua vez, $\alpha^{t}$ corresponde à produtividade do trabalho da economia como um todo, e $\alpha_{F}^{t}, \alpha_{I}^{t}, \alpha_{O}^{t}$ representam as respectivas produtividades do trabalho dos setores formal, informal e de outras unidades familiares.

As expressões de 1 a 5 são meras identidades e, nesse sentido, revelam apenas um maneira singular de decompor o valor adicionado da economia gerado ao longo do período compreendido entre 2000 e 2009. No entanto, essa forma de apresentação das informações nos permite investigar de maneira clara as repercussões da pergunta formulada anteriormente, ou seja, o que teria acontecido com o valor adicionado e com a produtividade do trabalho agregados se todas as ocupações que foram criadas nos anos 2000 tivessem sido alocadas no setor formal?

Essa questão e os exercícios contrafactuais que ela enseja trazem para o centro do debate o problema da heterogeneidade estrutural, aqui represen- 
tado pelos diferencias de produtividade entre os setores formal, informal e outras unidades familiares. Ademais, propicia uma reflexão importante acerca dos estímulos tanto para a formalização de trabalhadores quanto de empresas, sobre as políticas públicas voltadas para capacitação e adaptação de trabalhadores que migram entre setores, assim como sobre as políticas de incentivo à obtenção de ganhos de produtividade, como se verá adiante.

Do ponto de vista matemático, a simulação proposta em nosso primeiro exercício contrafactual requer uma reformulação da estratégia de decomposição do valor adicionado capaz de absorver a pergunta estabelecida, isto é, que esteja apta a incorporar no setor formal o emprego gerado nos setores informal e de outras unidades familiares. Além disso, requer igualmente uma hipótese acerca da natureza da produtividade do trabalho, ou seja, se esta pertence ao trabalhador ou se está vinculada à tecnologia incorporada em máquinas e equipamentos e à organização do processo de trabalho de cada setor ou, ainda, alguma versão intermediária entre as duas hipóteses.

Preliminarmente, iremos supor que a produtividade do trabalho está estritamente relacionada ao setor de produção, de modo que os empregados que se transferem dos demais setores para o setor formal da economia o fazem com a produtividade deste último. ${ }^{13}$

Com o intuito de facilitar o exercício, podemos reescrever o valor adicionado em $t$ como o resultado da multiplicação da produtividade do trabalho em t pelo estoque de ocupações em t-1 mais a variação das ocupações entre t e $t-1$. Neste sentido, temos que:

$$
Y^{t}=\alpha_{F}^{t} \cdot\left(N_{F}^{t-1}+\Delta N_{F}^{t}\right)+\alpha_{I}^{t} \cdot\left(N_{I}^{t-1}+\Delta N_{I}^{t}\right)+\alpha_{O}^{t} \cdot\left(N_{O}^{t-1}+\Delta N_{O}^{t}\right)
$$

Para sabermos o que teria acontecido com o valor adicionado e com a produtividade do trabalho agregados se todas as ocupações que foram criadas nos anos 2000 tivessem sido alocadas no setor formal, precisamos realocar $\Delta N_{I}^{t}$ e $\Delta N_{O}^{t}$ para o setor formal. Formalmente, isso significa dizer que:

$$
\begin{aligned}
& Y^{t^{\prime}}=\alpha_{F}^{t} \cdot\left[\left(N_{F}^{t-1}+\Delta N_{F}^{t}\right)+\left(\Delta N_{I}^{t}+\Delta N_{O}^{t}\right)\right]+\alpha_{I}^{t} \cdot\left(N_{I}^{t-1}-\Delta N_{I}^{t}\right)+ \\
& +\alpha_{O}^{t} \cdot\left(N_{O}^{t-1}-\Delta N_{O}^{t}\right)
\end{aligned}
$$

13 Esta hipótese será flexibilizada mais adiante. 
Generalizando: $Y^{t^{\prime}}=\left[\alpha_{m}^{t} \cdot\left(N_{m}^{t-1}+\sum_{i=1}^{m} \Delta N_{i}^{t}\right)\right]+\left[\sum_{i=1}^{m-1} \alpha_{i}^{t} \cdot\left(N_{i}^{t-1}-\Delta N_{i}^{t}\right)\right]$

Note que o novo valor adicionado da economia mantem as produtividades setoriais e o estoque total de ocupações. $\bigcirc$ único elemento a alterá-lo é a migração dos empregos gerados nos setores informal e outras unidades familiares para o setor formal. Nesse caso, fica claro que tanto o valor adicionado $\left(Y^{t^{\prime}}\right)$ quanto a produtividade $\left(\alpha^{t^{\prime}}\right)$ totais da economia serão maiores após a migração de trabalhadores do que antes $\left(Y^{t^{\prime}}>Y^{t} ; \alpha^{t^{\prime}}>\alpha^{t}\right)$ uma vez que, conforme a tabela $1, \alpha_{F}^{t}>\alpha_{O}^{t}>\alpha_{I}^{t}$.

O segundo exercício contrafactual a ser realizado procura relaxar a hipótese de que a produtividade do trabalho está estritamente relacionada ao setor de produção. Isto porque é razoável supor que se, por um lado, a geração de valor adicionado está associada à tecnologia incorporada em máquinas e equipamentos e à organização do processo de trabalho de cada setor, por outro, as habilidades individuais inatas e aquelas adquiridas por meio da educação formal e do treinamento para o trabalho ao longo da vida laboral de cada indivíduo também são elementos que influenciam a produtividade do trabalho e, portanto, a formação do valor adicionado. Suponhamos que a migração intersetorial das novas ocupações geradas se fará com a produtividade média " $\beta^{t}$ " (aritmética ou ponderada) entre os setores formal, informal e outras unidades familiares. Tal como antes, iremos realocar $\Delta N_{I}^{t}$ e $\Delta N_{O}^{t}$ para o setor formal. Porém, neste exercício, os trabalhadores migrantes não passarão a desempenhar suas atividades com a produtividade do setor de destino, mas sim com a produtividade média intersetorial, de modo que o novo valor adicionado será dado por:

$$
Y^{t^{\prime \prime}}=\alpha_{m}^{t} \cdot\left(N_{m}^{t-1}+\Delta N_{m}^{t}\right)+\left(\sum_{i=1}^{m-1} \beta^{t} \cdot \Delta N_{i}^{t}\right)+\sum_{i=1}^{m-1} \alpha_{i}^{t} \cdot\left(N_{i}^{t-1}-\Delta N_{i}^{t}\right)
$$

Como $\alpha_{F}^{t}>\alpha_{O}^{t}>\alpha_{I}^{t}$, então $\beta^{t}<\alpha_{F}^{t}$, o que fará com que o valor adicionado e a produtividade agregada, ainda que maiores que o valor adicionado e a produtividade históricos, sejam menores do que aqueles verificados no primeiro exercício $Y^{t^{\prime}}>Y^{t^{\prime \prime}}>Y^{t} ; \alpha^{t^{\prime}}>\alpha^{t^{\prime \prime}}>\alpha^{t}$.

As possibilidades de simulações são inúmeras, contudo, optou-se aqui por simular simultaneamente a migração das ocupações para o setor formal e a migração das ocupações entre atividades. 
No terceiro exercício contrafactual de nosso artigo faremos com que as ocupações geradas no período sejam transferidas para o setor formal de acordo com a proporção " $\theta_{j}^{t}$ " das ocupações de cada atividade nas ocupações totais. Além disso, retomaremos a hipótese inicial de que a produtividade do trabalho está estritamente relacionada ao setor de produção.

$$
Y^{t^{\prime \prime}}=\sum_{j=1}^{n}\left[\alpha_{j m}^{t} \cdot\left(N_{j m}^{t-1}+\Delta N_{j m}^{t}\right)+\sum_{i=1}^{m-1}\left(\theta_{j}^{t} \cdot \Delta N_{j i}^{t}\right)+\sum_{i=1}^{m-1} \alpha_{j i}^{t} \cdot\left(N_{j i}^{t-1}-\Delta N_{j i}^{t}\right)\right]
$$

Logo, não temos como saber a priori qual a relação entre os valores do exercício e os valores históricos do valor adicionado e da produtividade, porque o resultado final dependerá, por um lado, da proporção de emprego de cada atividade no emprego total da economia " $\theta_{j}^{t}$ " e, de outro, pelo modo como essa variável é mensurada, se pelo fluxo ou pelo estoque de emprego.

O último exercício contrafactual consiste em uma combinação dos exercícios 2 e 3 , pois se fará a simulação dos impactos das migrações de trabalhadores entre setores e atividades de acordo com a proporção das ocupações de cada atividade nas ocupações totais, levando-se em consideração que a produtividade do trabalhador que migra corresponde à produtividade média entre os setores de cada atividade.

Portanto, iremos realocar $\Delta N_{I}^{t}$ e $\Delta N_{O}^{t}$ para o setor formal, porém agora na proporção " $\theta_{j}^{t}$ " do emprego de cada atividade no emprego total e de acordo com a produtividade média entre setores de cada atividade " $\beta_{j i}^{t}$ " antes da migração, de modo que:

$$
\begin{aligned}
& Y^{t^{\prime \prime \prime}}=\sum_{j=1}^{n}\left\{\alpha_{j m}^{t} \cdot\left(N_{j m}^{t-1}+\Delta N_{j m}^{t}\right)+\sum_{i=1}^{m-1}\left(\beta_{j}^{t} \cdot \theta_{j}^{t} \cdot \Delta N_{j i}^{t}\right)+\right. \\
& \left.+\sum_{i=1}^{m-1}\left[\alpha_{j i}^{t} \cdot\left(N_{j i}^{t-1}-\Delta N_{j i}^{t}\right)\right]\right\}
\end{aligned}
$$

Tal como no terceiro caso, não temos como saber a priori qual a relação entre os valores deste exercício contrafactual e os valores históricos. Os motivos são basicamente os mesmos, acrescentados do fato de que estamos trabalhando com a produtividade média setorial de cada atividade e não apenas com a produtividade do setor formal.

Uma vez realizados os exercícios de decomposição do valor adicionado e algumas das possibilidades contrafactuais, cabe ilustrar o que teria acontecido na economia brasileira se todas as ocupações criadas nos anos 2000 
tivessem sido alocadas no setor formal. Dedicamo-nos a essas simulações na seção a seguir.

\subsection{Resultados dos exercícios contrafactuais}

Nesta subseção procuramos simular, com base nas informações das contas nacionais, o que teria acontecido com a economia brasileira se todos os empregos criados entre 2000 e 2009 tivessem sido gerados no setor formal. Nosso ponto de partida é, evidentemente, recalcular o valor adicionado a partir dos exercícios contrafactuais propostos. A ideia subjacente por trás de todo exercício é que a heterogeneidade estrutural reduz o potencial de crescimento e que políticas públicas voltadas para a redução dos diferenciais de produtividade entre atividades teriam efeitos positivos sobre a trajetória da economia. Uma das formas de promover tal redução é, certamente, por meio da formalização de atividades e ocupações, tendo em vista o peso que os setores informal e de outras unidades familiares têm em algumas atividades e a enorme assimetria de produtividade entre eles e o setor formal.

Os dados do gráfico 1 mostram três situações possíveis, relativas às hipóteses distintas sobre o nível de produtividade dos trabalhadores que migram de setor, além dos resultados verificados. No painel 1a apresentamos o valor adicionado verificado (histórico) e três cenários alternativos. No cenário 1, simulamos o que teria acontecido com o VA total e setorial se todos os empregos tivessem sido criados no setor formal e se todos os trabalhadores desempenhassem suas funções com a produtividade desse setor, antes da migração. $O$ cenário 2 revela o que teria acontecido se a produtividade dos trabalhadores transferidos para o setor formal correspondesse à produtividade média simples dos três setores antes da migração. Por sua vez, o cenário 3 mostra a trajetória do VA total e setorial, assumindo que os novos trabalhadores desempenham suas atividades com a produtividade média ponderada dos setores antes da migração. Por fim, vale dizer que exercício análogo foi feito para os setores formal (1b), informal (1c) e outras unidades familiares (1d) e que tais cenários correspondem aos exercícios contrafactuais 1 e 2 .

O gráfico 1a revela que a simples migração de trabalhadores para o setor formal implicaria um deslocamento para cima da curva de VA, elevando o nível do produto agregado da economia. No entanto, o nível do valor adi- 
cionado seria mais elevado se a relação entre a produtividade do trabalho e o setor produtivo fosse mais intensa ou, alternativamente, quanto maior e mais rápido fosse o processo de adaptação dos trabalhadores que migram dos setores informal e de outras unidades familiares para o segmento formal. Note que se a produtividade adotada pelos trabalhadores que migram fosse igual a do setor formal (cenário 1), a taxa de crescimento acumulada do VA entre 2000 e 2009 aumentaria de $31,8 \%$ para $35,9 \%$, ao passo que se a produtividade média fosse adotada teríamos um crescimento do VA de $33,8 \%$, no caso da média simples (cenário 2), e de $34,1 \%$, para o caso da média ponderada (cenário 3).

No gráfico $1 \mathrm{~b}$ é possível constatar que haveria um aumento no valor adicionado do setor formal, cuja magnitude depende da produtividade com a qual os trabalhadores que migraram para esse setor passam a trabalhar. Por sua vez, os gráficos 1c e $1 \mathrm{~d}$ revelam a redução de valor adicionado que ocorreria nos setores informal e de outras unidades familiares em decorrência da migração de trabalhadores.

As informações contidas nos gráficos 1a, 1b, 1c e 1d indicam que a transferência de trabalhadores para o setor formal da economia teria repercussões positivas sobre a trajetória de crescimento, cuja intensidade depende fundamentalmente da capacidade de aprendizado dos trabalhadores às novas tarefas e rotinas administrativas e operacionais desse segmento. Poderíamos dizer, tal como Abramovitz (1986), que as chamadas social capabilities cumprem um papel importante na apropriação de conhecimento, seja ele advindo da fronteira tecnológica, seja proveniente de setores produtivos tecnológica e organizacionalmente mais avançados. Políticas que incentivam a formalização de empresas, por um lado, e que ampliam a escolaridade básica e propiciam a formação para o mercado de trabalho, por outro, poderiam cumprir um papel relevante no aumento do valor adicionado da economia.

A ampliação do valor adicionado nos exercícios de simulação tem impactos semelhantes na produtividade agregada e do setor formal, ainda que para os segmentos informal e de outras unidades familiares não se verifique qualquer modificação nos níveis de produtividade em relação àquela observada historicamente.

No primeiro caso, o aumento da produtividade agregada decorreu da migração de trabalhadores para o setor formal, cuja incorporação foi feita com níveis de produtividade muito superiores aos dos seus setores de ori- 
Gráfico 1 Valor adicionado: valores históricos e simulações setoriais e para o agregado da economia - 2000-2009 (em R\$ milhões)

\section{(a) Total}

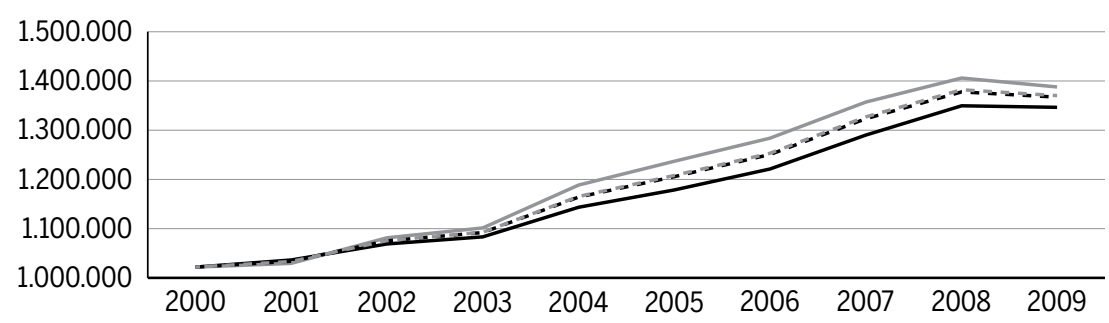

\section{(b) Formal}

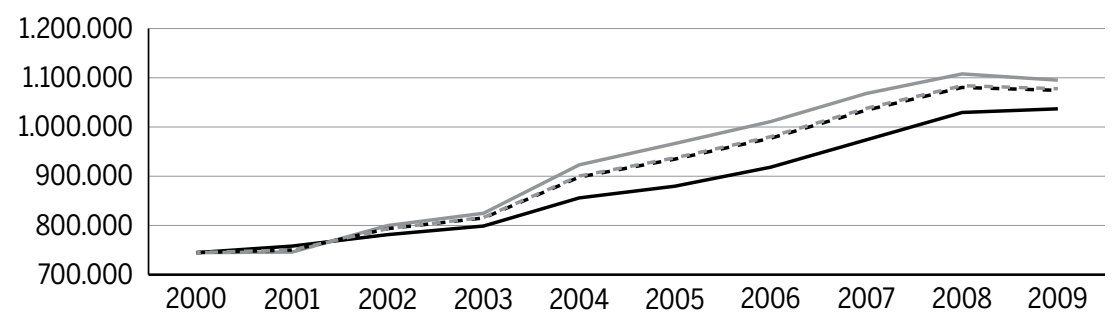

(c) Informal

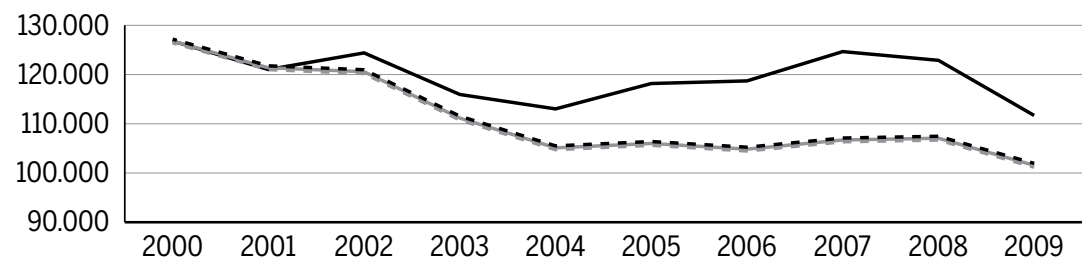

(d) Outras unidades familiares

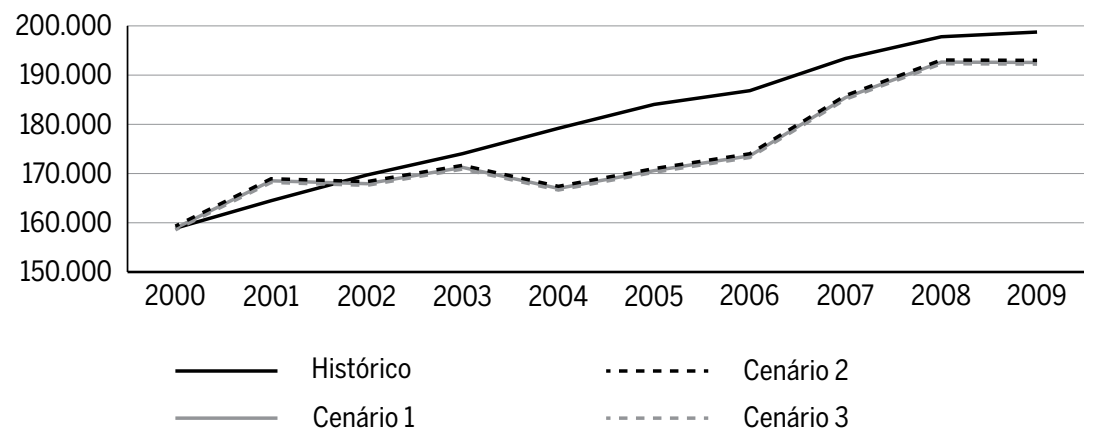

Fonte: IBGE. Elaboração dos autores. 
Gráfico 2 Produtividade agregada histórica e simulações - 2000-2009

(em R\$ mil por ocupação, preços de 2000)

\section{(a) Total}

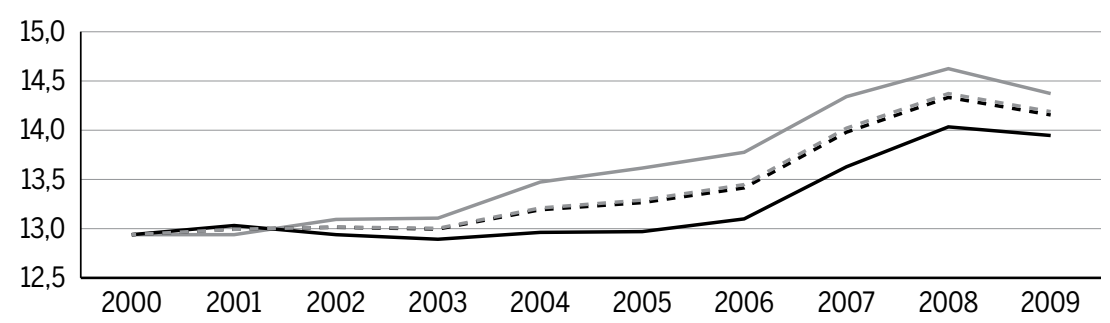

\section{(b) Formal}

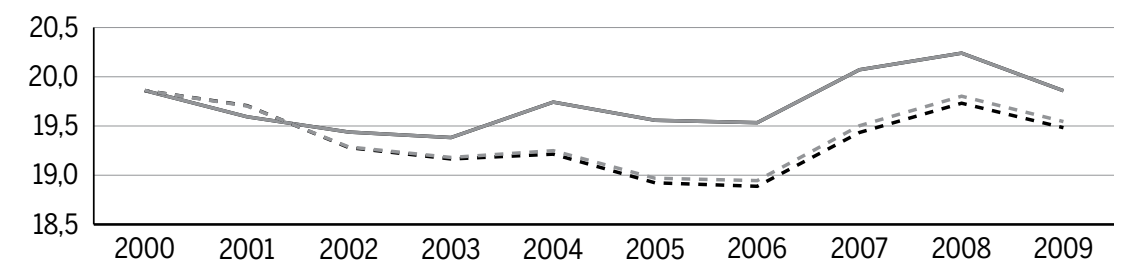

\section{(c) Informal}

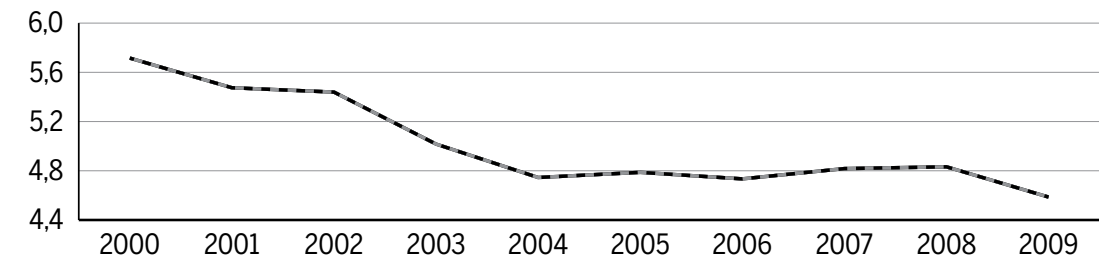

\section{(d) Outras unidades familiares}

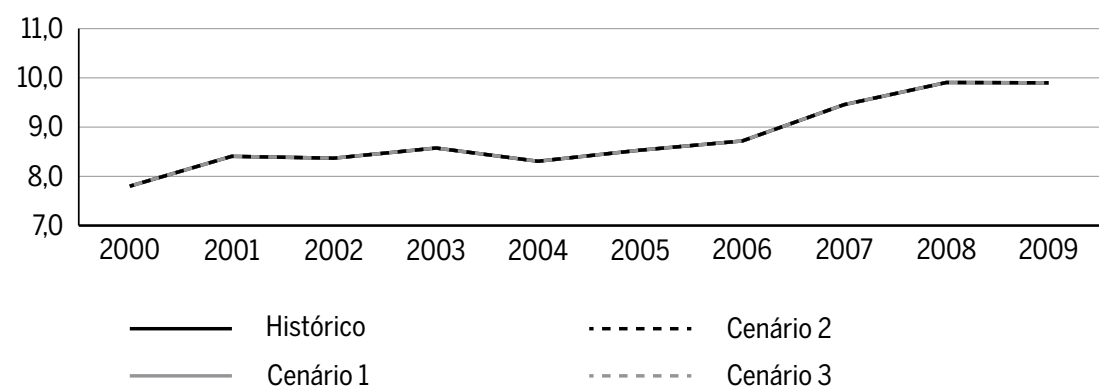

Fonte: IBGE. Elaboração dos autores. 
gem. Ademais, como a ocupação total não se alterou, o aumento do valor adicionado foi integralmente repassado à produtividade. No caso do setor formal, embora nossos exercícios contrafactuais tenham ampliado o nível de ocupação do setor, o crescimento do valor adicionado foi mais do que proporcional ao aumento da ocupação, mais precisamente, na magnitude da produtividade atribuída aos novos trabalhadores, de modo que se verificou uma ampliação da produtividade do setor em relação ao seu valor histórico.

Por fim, como era de se esperar, nenhum dos exercícios contrafactuais alterou a produtividade dos setores informal e de outras unidades familiares, porque a redução da ocupação decorrente da migração de trabalhadores do setor formal acarretou uma redução equivalente do valor adicionado.

As simulações apresentadas até o momento capturaram os impactos potenciais sobre valor adicionado e produtividade agregados de migrações hipotéticas do fluxo de trabalhadores dos setores informal e de outras unidades familiares para o setor formal. Todavia, a clivagem formal versus informal é pouco ilustrativa se não for cotejada com informações atinentes às atividades econômicas, cujos valores adicionados e produtividades refletem trajetórias tecnológicas e intensidades no uso dos fatores produtivos muito diferenciadas. Assim, cabe indagar quais os impactos da formalização sobre o valor adicionado e a produtividade das atividades econômicas.

Com o intuito de responder a essa questão, duas estratégias foram empregadas de forma complementar às já utilizadas. Na primeira estratégia, e em linha com as proposições dos exercícios contrafactuais 3 e 4 , ponderou-se a variação das ocupações nos setores informal e de outras unidades familiares pela participação de cada atividade no estoque total de trabalhadores. Na segunda estratégia, ponderou-se aquela variação pela participação de cada atividade no fluxo total de trabalhadores no ano.

Os cenários obtidos a partir da ponderação das variações das ocupações pelas participações das atividades no estoque de ocupações produzem informações interessantes sobre o comportamento da estrutura produtiva, na hipótese de que a mesma tivesse sido submetida a uma migração de trabalhadores para o setor formal. Em quase todos os cenários, o valor adicionado simulado de cada atividade superou seu respectivo valor histórico, com destaque para os aumentos pronunciados dos valores obtidos nas simulações para a "Agropecuária" e para as "Atividades imobiliárias e aluguéis". A grande exceção ficou por conta dos "Serviços domésticos", cujo valor adicionado simulado foi, em 2009, 29\% inferior ao efetivamen- 
te verificado, para qualquer cenário analisado. Cabe mencionar também que as atividades "Serviços de informação" e "Outros serviços" apresentaram valores adicionados ligeiramente inferiores nos cenários 2 e 3 aos registrados historicamente.

É importante notar que uma eventual migração de trabalhadores para o setor formal dentro de cada atividade e entre elas também teria provocado alterações na produtividade, ainda que suas respectivas trajetórias não tivessem se alterado significativamente. De acordo com os dados da tabela 3 , nota-se que a maior parte dos cenários apresenta níveis de produtividade das atividades superiores aos efetivamente verificados, destacando-se, novamente, os incrementos expressivos nos valores alcançados pelas simulações da "Agropecuária" e das "Atividades imobiliárias e aluguéis".

Mais uma vez, as exceções ficaram por conta dos "Serviços domésticos" (grande destaque negativo), dos "Serviços de informação" e dos "Outros serviços" que apresentaram produtividades inferiores às observadas historicamente em quase todos os cenários.

No que diz respeito aos cenários obtidos a partir da ponderação das variações das ocupações pelas participações das atividades no fluxo de ocupações geradas, notam-se algumas alterações expressivas, tanto em relação aos valores historicamente observados, quanto relativamente aos valores atingidos a partir da ponderação pelo estoque de trabalho (tabela 4). Na maior parte dos cenários, o valor adicionado simulado de cada atividade superou seu respectivo valor histórico, com ênfase na elevação expressiva dos valores obtidos nas simulações para a "Indústria extrativa", "Produção e distribuição de eletricidade e gás, água, esgoto e limpeza urbana" e para as "Atividades imobiliárias e aluguéis". A grande exceção ficou por conta dos "Serviços domésticos", cujo valor adicionado simulado foi, em 2009, 29\% inferior ao efetivamente verificado, para qualquer cenário analisado. Ademais, é digno de nota o fato de que as atividades "Indústria de transformação", "Serviços de informação" e "Outros serviços" também tenham apresentado valores adicionados inferiores aos registrados historicamente.

Além disso, de acordo com os dados da tabela 5, nota-se que a maioria dos cenários apresentou níveis de produtividade superiores aos efetivamente verificados, destacando-se, desta vez, os incrementos expressivos nos valores alcançados pelas simulações para a "Indústria extrativa", para "Produção e distribuição de eletricidade e gás, água, esgoto e limpeza urba- 


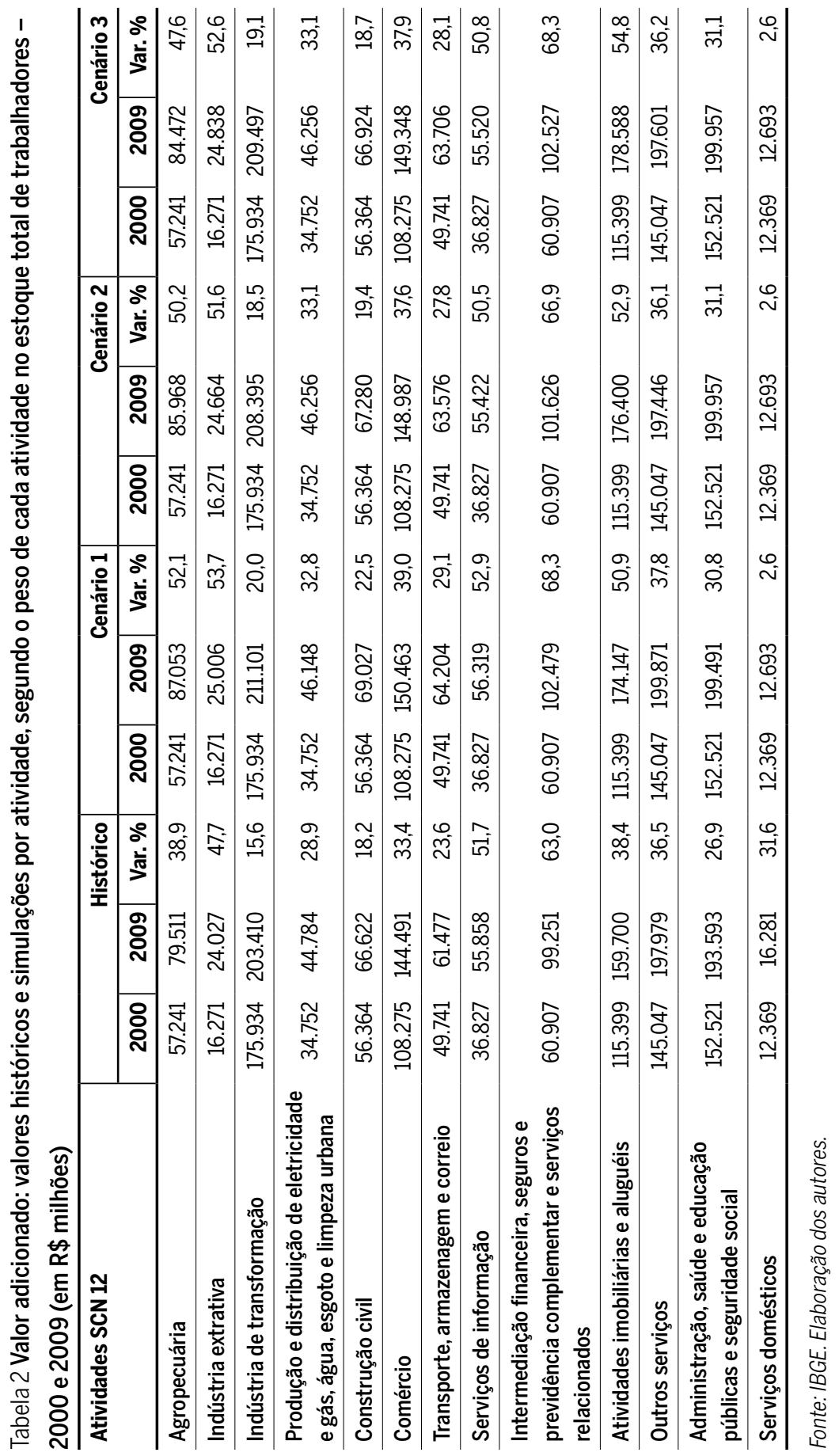




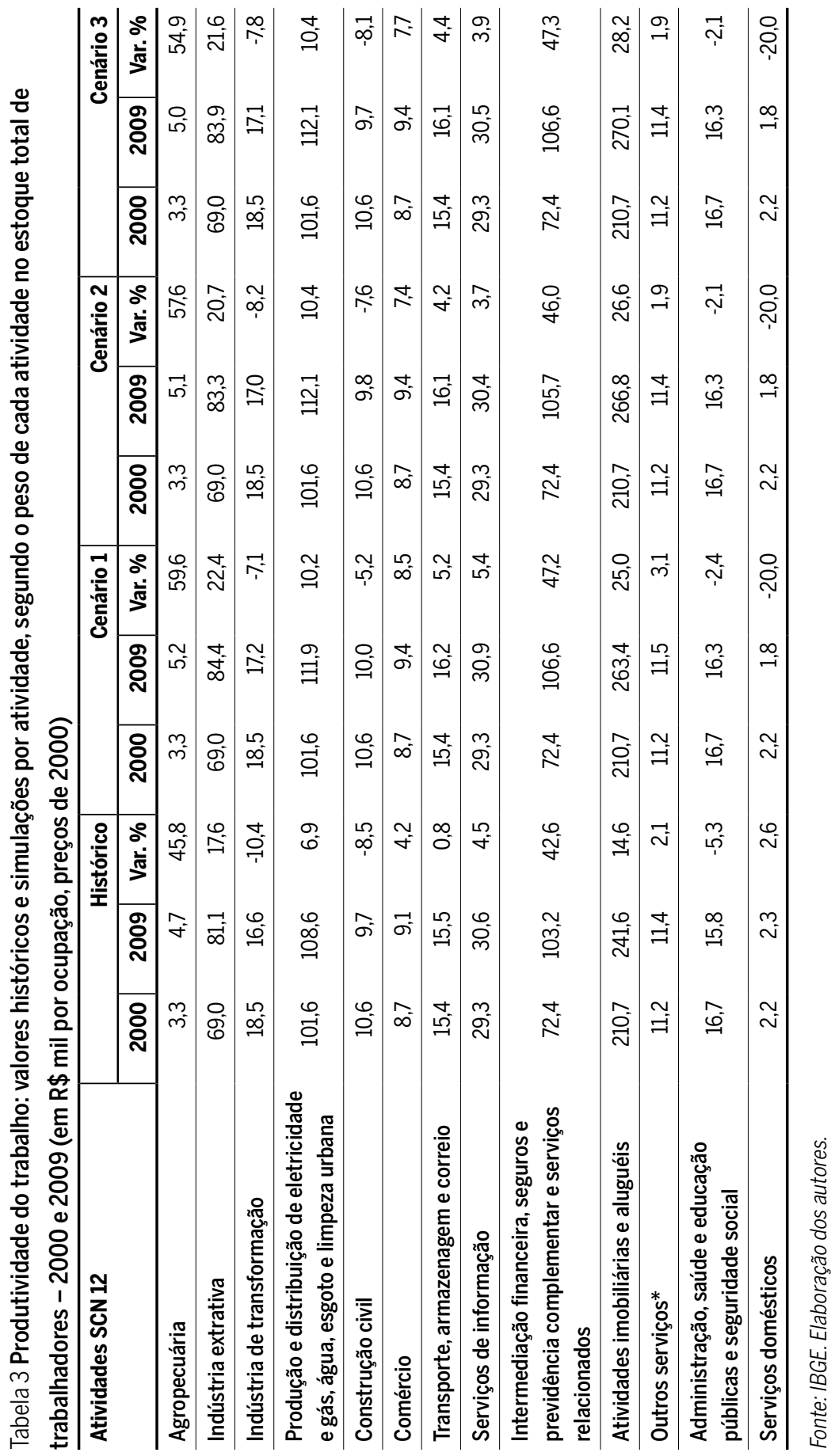




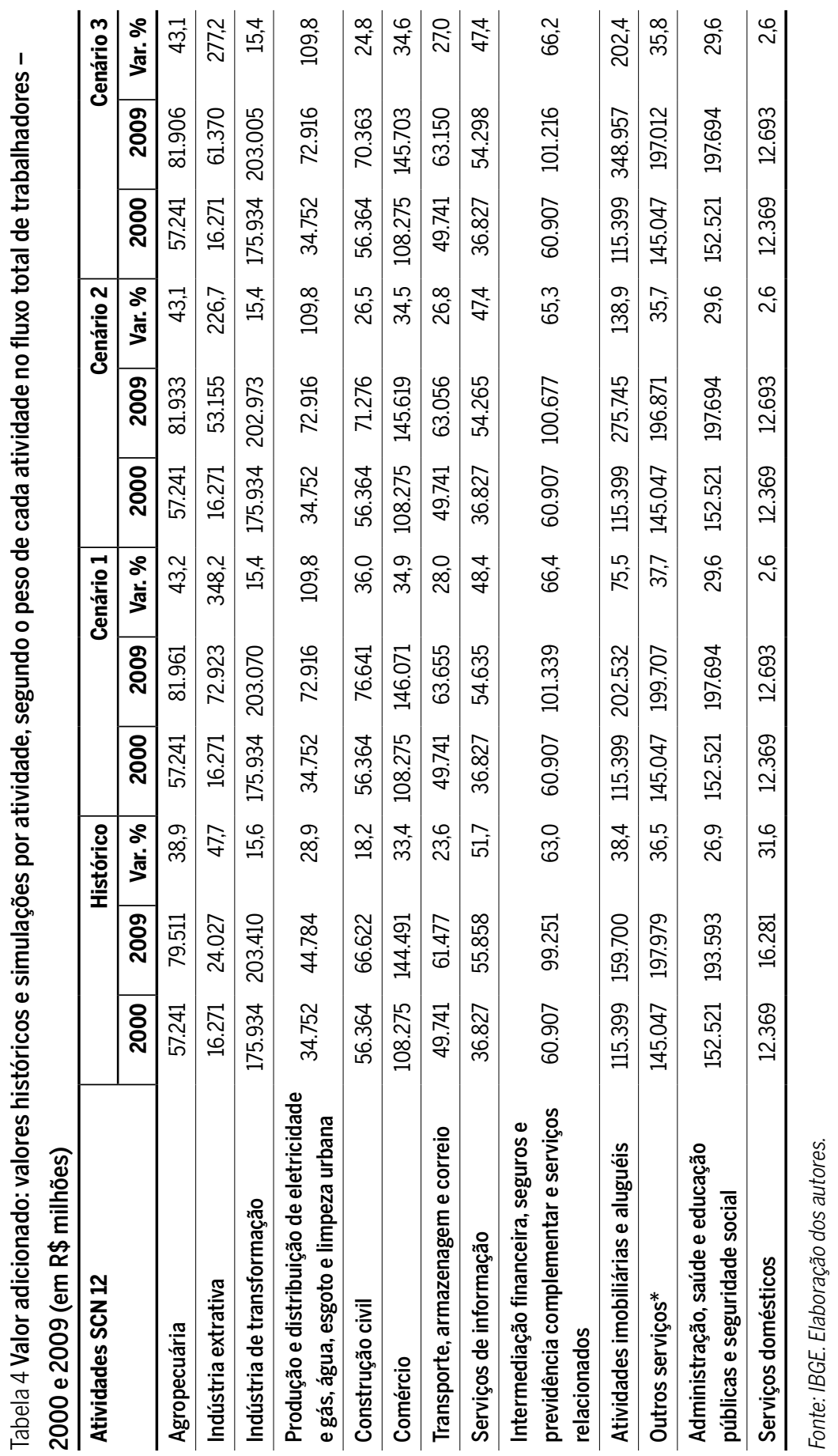




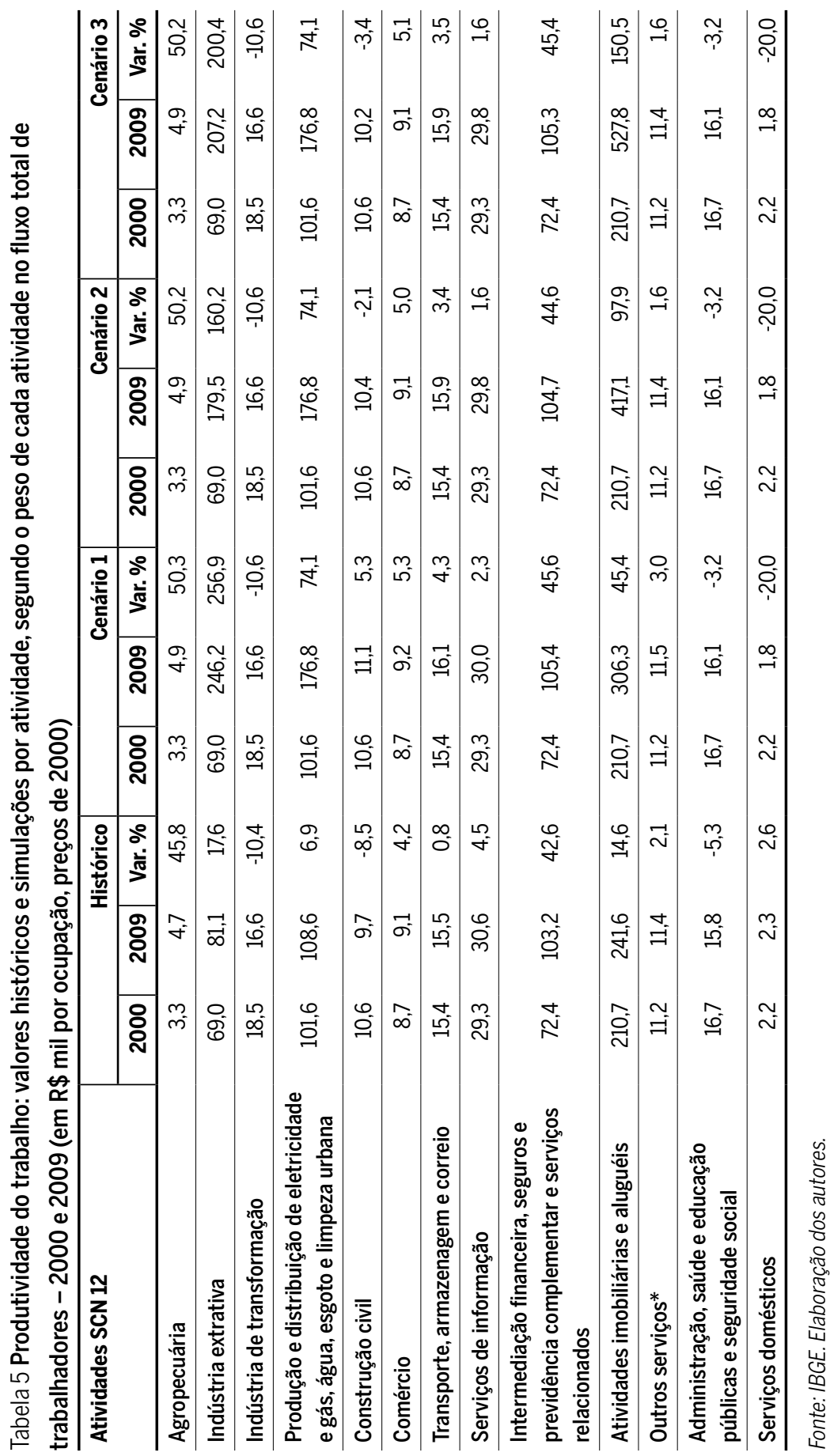


na" e para as "Atividades imobiliárias e aluguéis". Certamente, o fato mais marcante dessa simulação se refere ao aumento do nível da produtividade do trabalho para a "Indústria extrativa" e para "Produção e distribuição de eletricidade e gás, água, esgoto e limpeza urbana", assim como para as "Atividades imobiliárias e aluguéis".

Por fim, tendo em vista a importância da indústria de transformação no debate contemporâneo sobre estratégias de desenvolvimento e toda a discussão recente sobre a existência ou não de uma eventual desindustrialização no Brasil, seria oportuno tecer alguns comentários mais específicos sobre essa atividade.

\section{0 caso da indústria de transformação}

Embora as simulações realizadas não tenham alterado significativamente a trajetória tanto do valor adicionado quanto da produtividade, cabe notar que uma eventual maior formalização das empresas que operam na indústria de transformação teria mitigado boa parte dos problemas dessa atividade entre 2000 e 2009 como mostram os gráficos a seguir.

Note que, a despeito da trajetória ascendente do valor adicionado dessa atividade (seja ponderado pelo estoque, seja ponderado pelo fluxo de ocupações), a produtividade da indústria de transformação teve um comportamento bastante errático, chegando ao final do período com um nível inferior ao verificado no início.

Gráfico 3 Valor adicionado e produtividade do trabalho: valores históricos e simulações para a indústria de transformação - 2000-2009

\section{(a) Total}

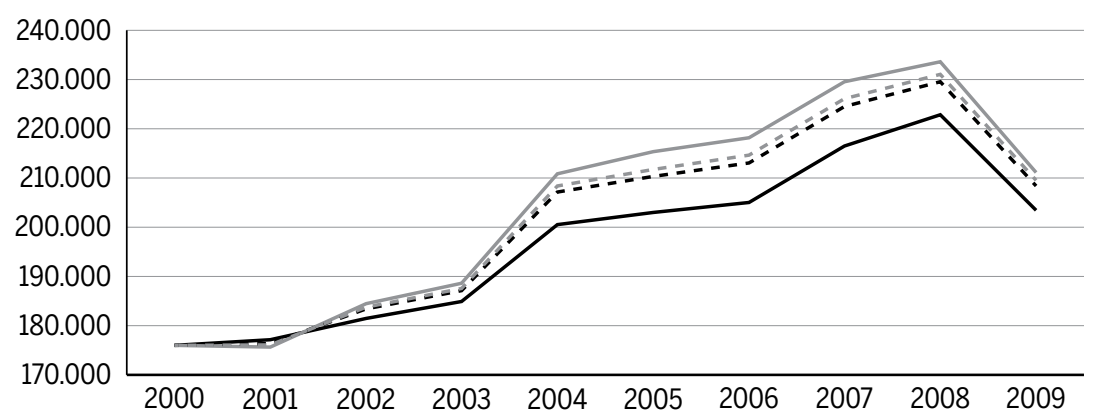




\section{(b) Formal}

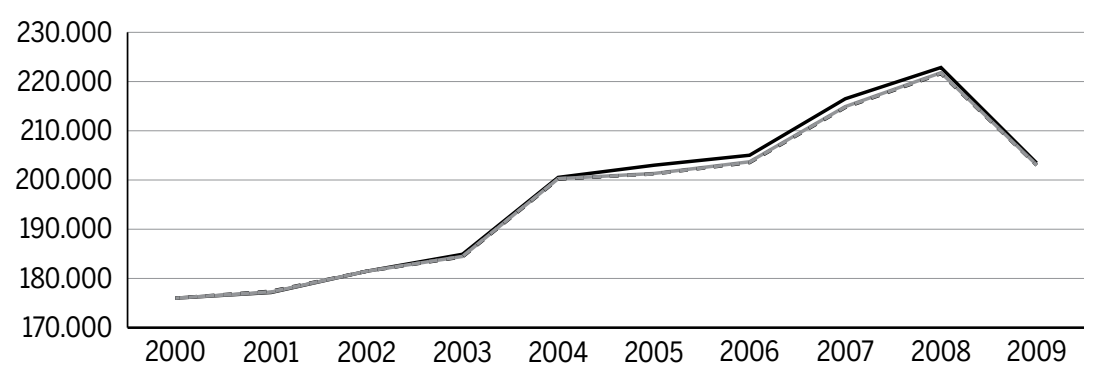

\section{(c) Informal}

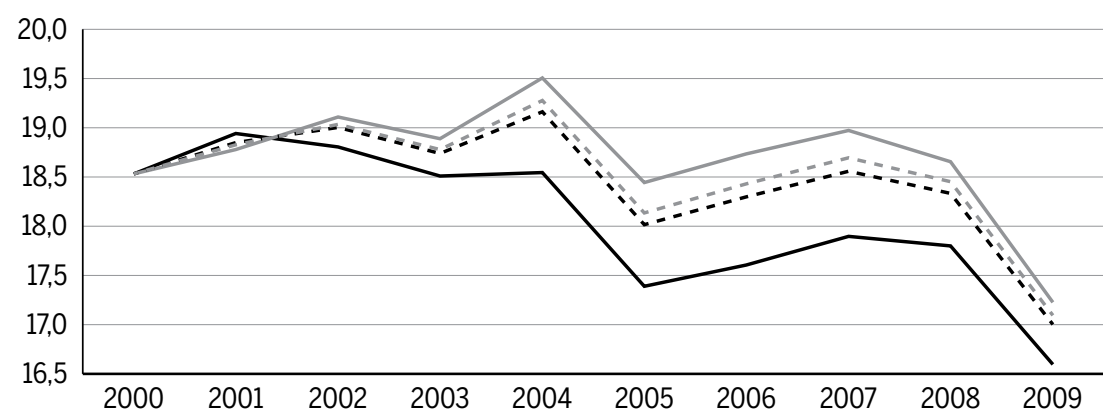

\section{(d) Outras unidades familiares}

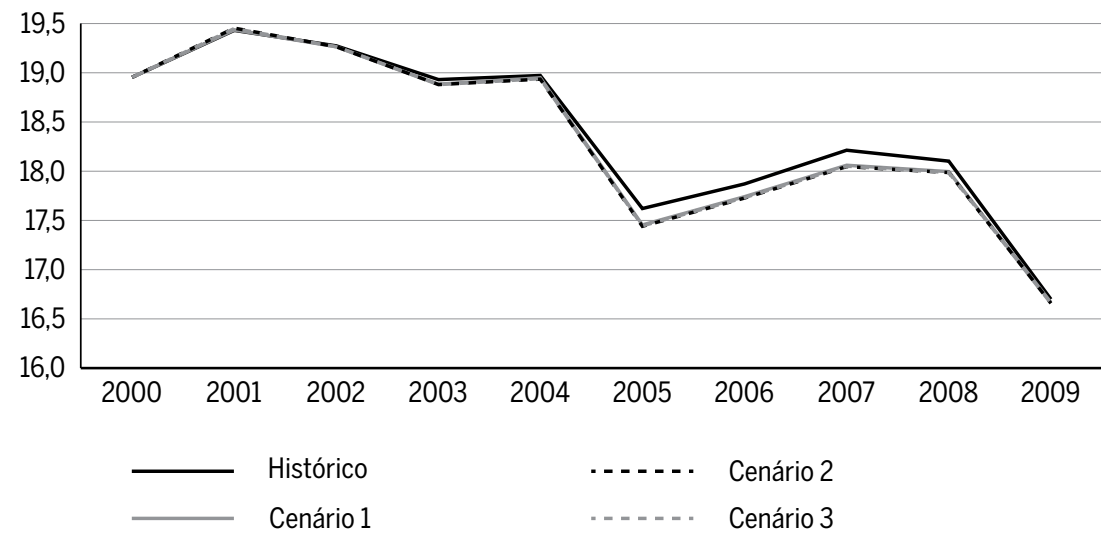

Fonte: IBGE. Elaboração dos autores.

Nota: valor adicionado em $R$ \$ milhões e produtividade em $R$ \$ mil por ocupação, a preços de 2000.

Contudo, os exercícios de simulação sugerem que se as ocupações geradas nos demais setores tivessem sido alocadas no setor formal da indústria de 
acordo com sua proporção no estoque de emprego, o nível de produtividade em 2009 teria sido bem mais próximo de 2000 do que aquele verificado historicamente.

Outro aspecto que chama a atenção na trajetória da produtividade do trabalho tem a ver com a relação entre a produtividade e o grau de utilização da capacidade produtiva. Como bem observado por Lavoie (2014) "The overall productivity per worker is an increasing function of the rate of utilization of capacity" (2014; 325).

Embora a construção analítica de Lavoie seja complexa e vinculada à distinção entre trabalho variável e trabalho "semi-constante", os chamados overhead labor costs, é possível demonstrar a existência de tal relação simplesmente por meio de uma pequena modificação na identidade do produto agregado apresentada anteriormente.

De acordo com a equação (4), sabe-se que o nível do valor adicionado corresponde à produtividade do trabalho multiplicada pelo estoque de ocupações $\left(Y^{t}=\alpha^{t} \cdot N^{t}\right)$. Porém, se multiplicarmos e dividirmos a produtividade $\left(\alpha^{t}\right)$ pelo produto potencial ou capacidade produtiva $\left(\overline{Y^{t}}\right)$, teremos que:

$$
\alpha^{t}=\frac{Y^{t}}{N^{t}} \cdot \frac{\overline{Y^{t}}}{\overline{Y^{t}}} \therefore \alpha^{t}=\frac{\overline{Y^{t}}}{N^{t}} \cdot \frac{Y^{t}}{\overline{Y^{t}}} \therefore \alpha^{t}=\overline{\alpha^{t}} \cdot u^{t}
$$

em que $\overline{\alpha^{t}}=\frac{\overline{Y^{t}}}{\overline{N^{t}}}$ e $u^{t}=\frac{Y^{t}}{\overline{Y^{t}}}$.

A equação (11) revela que a produtividade do trabalho observada ou efetiva depende, de um lado, daquilo que poderíamos chamar de produtividade técnica. Ela estaria associada ao nível máximo de capacidade produtiva que depende, entre outras coisas, de fatores de longo prazo, tais como a tecnologia empregada no processo produtivo, as formas de organização da produção, as instituições e a composição setorial da produção. ${ }^{14}$ De outro lado, a produtividade do trabalho efetiva depende de um fator de curto prazo, o grau de utilização da capacidade produtiva, cujo principal determinante é a demanda por bens e serviços.

A partir da equação (11) e utilizando os dados de valor adicionado das contas nacionais anteriormente descritos, assim como o grau de utilização da capacidade produtiva fornecido pela Fundação Getúlio Var14 É importante notar que esses fatores de longo prazo também estão associados a elementos de demanda, como nos mostra a lei de Kaldor-Verdoorn. Veja a esse respeito, Amitrano (2013). 
gas, ${ }^{15}$ é possível observar o que aconteceu tanto com a produtividade técnica quanto com a efetiva na indústria de transformação entre 2000 e 2009.

O gráfico 4 mostra claramente que a intensa queda no grau de utilização da capacidade entre 2000 e 2002 amplificou a distância entre a produtividade técnica e a efetiva, fazendo com que a indústria perdesse competitividade e com que a produtividade deixasse de contribuir para a redução da inflação. ${ }^{16}$ Por outro lado, entre 2003 e 2008, o aumento do grau de utilização da capacidade reverteu, ainda que moderadamente, a estagnação da produtividade técnica, ampliando a competitividade da indústria de transformação e a contribuição da produtividade efetiva do trabalho no combate à inflação.

\section{Gráfico 4 Produtividade efetiva, técnica e grau de utilização da capacidade produtiva}

\section{na indústria de transformação brasileira - 2000-2009}

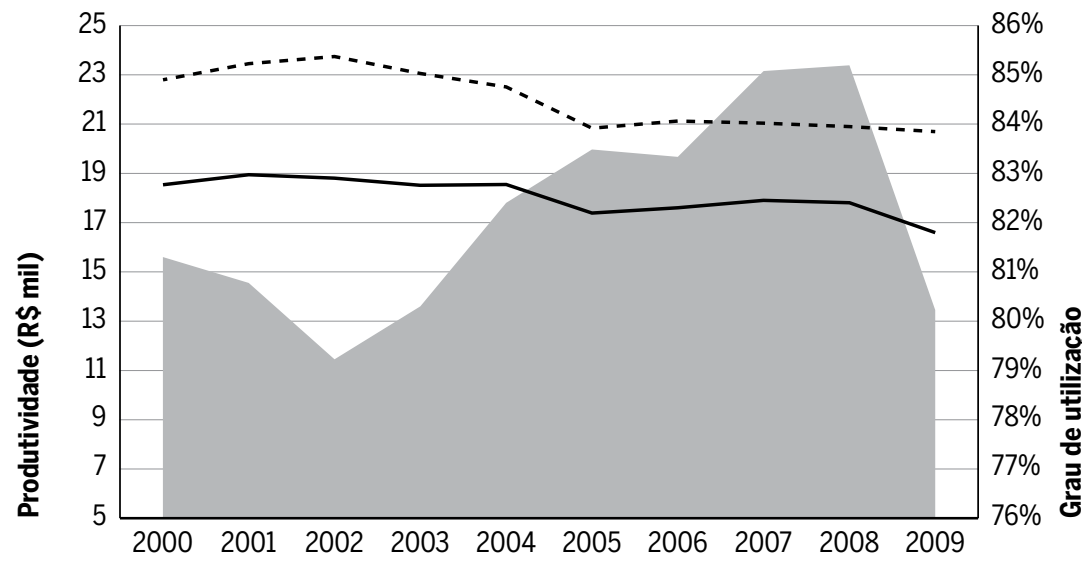

Fonte: IBGE; FGV. Elaboração própria.

Nota: produtividade em $R \$$ mil por ocupação, a preços de 2000.

15 No Brasil, as estatísticas sobre o grau de utilização da capacidade produtiva são muito precárias e dizem respeito apenas ao segmento formal da indústria. Tanto a Fundação Getúlio Vargas como a Confederação Nacional da Indústria apresentam séries longas de estatísticas para a indústria de transformação, embora recentemente tenham desenvolvido séries para a indústria extrativa. 16 É importante notar que em uma economia oligopolizada, com governo e aberta ao exterior, a trajetória dos preços livres depende da evolução dos mark-ups, da taxa de crescimento dos salários e da produtividade (custo real unitário do trabalho), da variação cambial e das modificações nas alíquotas tributárias). 
Esse novo olhar permite introduzir a demanda como fator explicativo não só da produtividade do trabalho, mas do valor adicionado em um contexto de heterogeneidade estrutural. Com isso podemos reescrever a identidade do produto (equação 5'), bem como todos os exercícios contrafactuais (equações 7', 8, 9 e 10) discutidos nas seções anteriores. Se tomarmos apenas as identidades 5', 7' e 8 e as reformularmos a partir da identidade entre produtividade efetiva, produtividade técnica e grau de utilização da capacidade produtiva, teremos que:

$$
\begin{aligned}
& Y^{t}=\sum_{i=1}^{m}\left(\overline{\alpha_{i}^{t}} \cdot u_{i}^{t}\right) \cdot N_{i}^{t} \\
& Y^{t^{\prime}}=\left[\overline{\alpha_{m}^{t}} \cdot u_{m}^{t} \cdot\left(N_{m}^{t-1}+\sum_{i=1}^{m} \Delta N_{i}^{t}\right)\right]+\left[\sum_{i=1}^{m-1} \overline{\alpha_{i}^{t}} \cdot u_{i}^{t} \cdot\left(N_{i}^{t-1}-\Delta N_{i}^{t}\right)\right] \\
& Y^{t^{\prime}}=u_{m}^{t} \cdot\left[\overline{\left(\alpha_{m}^{t}\right)} \cdot\left(N_{m}^{t-1}+\Delta N_{m}^{t}\right)+\left(\sum_{i=1}^{m-1} \overline{\beta^{t}} \cdot \Delta N_{i}^{t}\right)\right]+ \\
& +\left[\sum_{i=1}^{m-1} \overline{\alpha_{i}^{t}} \cdot u_{i}^{t} \cdot\left(N_{i}^{t-1}-\Delta N_{i}^{t}\right)\right]
\end{aligned}
$$

em que $u_{m}^{t}>u_{m-h}^{t} \forall h=1 ; 2 ; 3 ; \ldots ; m-1$.

Neste caso, é possível perceber que mudanças positivas no grau de utilização da capacidade produtiva do setor formal superiores as do informal ampliariam a produtividade efetiva e o valor adicionado em todos os exercícios de simulação realizados.

\section{Considerações finais}

Neste trabalho foi apresentada uma nova metodologia de construção do valor adicionado, das ocupações e da produtividade do trabalho nos setores formal, informal e outras unidades familiares, desagregados por atividade econômica, com base nos dados do Sistema de Contas Nacionais Anuais do IBGE.

Entre 2000 e 2009 foi possível constatar o aumento da participação do setor de produção formal no valor adicionado total que se reproduziu em menor medida nas ocupações totais. Entre as atividades econômicas formais que aumentaram sua participação, destacam-se "Comércio", "Admi- 
nistração pública" e de "Outros serviços". A contrapartida do aumento da formalidade foi uma redução muito próxima nos outros dois setores de produção e foram encontrados indícios de que a maior parte do processo de formalização ocorreu dentro das atividades econômicas.

No que tange à produtividade do trabalho, verificou-se uma enorme disparidade entre os setores e atividades, tanto em nível quanto em taxa de variação. Enquanto a produtividade do trabalho total foi da ordem de $\mathrm{R} \$ 13$ mil, os setores formal e informal apresentaram níveis de cerca de $\mathrm{R} \$$ 20 mil e R 5 mil, respectivamente. Ademais, constatou-se que "Indústria extrativa" formal e "Produção e distribuição de eletricidade e gás, água, esgoto e limpeza urbana" são atividades cuja produtividade foi aproximadamente oito vezes superior à produtividade média da economia, ao passo que o contrário foi verificado para todas as atividades informais. $\mathrm{O}$ crescimento da produtividade agregada de $0,8 \%$ a.a. decorreu, sobretudo, da dinâmica de outras unidades familiares, uma vez que no setor formal como um todo a produtividade permaneceu estagnada e que houve queda no setor informal. Complementarmente, na maioria das atividades formais houve aumento da produtividade do trabalho, com destaque para a Agropecuária; as mais relevantes exceções foram "Indústria de transformação" e "Construção civil". Já no setor informal, todas as atividades econômicas apresentaram queda de produtividade. Evidenciou-se, portanto, a manutenção da heterogeneidade estrutural brasileira, tanto nos níveis quanto nas taxas de variação da produtividade.

Essas evidências ensejaram a pergunta sobre o que teria acontecido com o valor adicionado e, sobretudo, com a produtividade do trabalho se todas as ocupações geradas durante os anos 2000 tivessem sido alocadas no setor formal. Com o intuito de responder a essa questão, foi desenvolvida uma metodologia de decomposição do valor adicionado e de construção de exercícios contrafactuais. Tais exercícios foram realizados assumindo que os trabalhadores migraram para o setor formal, ora sem distinção de atividade econômica, ora com esta distinção, com três níveis diferentes de produtividade: i) com a produtividade do setor formal; ii) com a produtividade média simples entre o setor de origem (informal ou outras unidades familiares) e o setor de destino (formal); e iii) com a produtividade média ponderada entre o setor de origem e o setor de destino.

Após a decomposição analítica dos exercícios contrafactuais foram realizadas simulações que permitiram concluir que a realocação das ocupações 
no setor formal teria, em geral, ampliado tanto o valor adicionado quanto a produtividade agregada e segundo atividades econômicas. Puderam-se constatar também que esses efeitos foram mais pronunciados quando se levaram em conta os fluxos de ocupações por atividade econômica ao invés dos estoques. No que concerne à indústria de transformação, embora as simulações realizadas não tenham alterado significativamente a trajetória tanto do valor adicionado quanto da produtividade, cabe notar que uma eventual maior formalização das empresas que operam nesta atividade teria mitigado boa parte dos problemas entre 2000 e 2009.

Por fim, empreendeu-se uma nova decomposição do valor adicionado e da produtividade, mostrando que a produtividade efetiva/observada do trabalho é resultado da multiplicação da produtividade técnica pelo grau de utilização da capacidade produtiva. Nesse caso, verificou-se que mudanças positivas no grau de utilização da capacidade produtiva do setor formal superiores as do informal ampliariam a produtividade efetiva e o valor adicionado em todos os exercícios de simulação realizados.

Logo, o presente trabalho, ao retomar o problema da heterogeneidade estrutural, sob o prisma dos diferenciais de produtividade entre os setores formal, informal e outras unidades familiares, propiciou uma reflexão importante acerca dos estímulos tanto para a formalização de trabalhadores quanto de empresas, sobre as políticas públicas voltadas para a capacitação e adaptação de trabalhadores que migram entre setores, assim como sobre as políticas de incentivo à obtenção de ganhos de produtividade.

\section{Referências}

AKERLOF, G.; YELLEN, J. Eds. Efficiency Wage Models of the Labor Market. Cambridge: Cambridge University Press, 1986.

ABRAMOVITZ, M. Catching up, forging ahead, and falling behind. The Journal of Economic History, v. 46, n. 02, p. 385-406, 1986.

AMITRANO, C. Regime de crescimento, restrição externa e financeirização: uma proposta de conciliação. Economia e Sociedade, Campinas, v. 22, n. 2 (48), p. 285-316, ago. 2013.

BARROS, R. P.; MELLO, R.; PERO, V. Informal labor contracts: a solution or a problem? Texto para Discussão, 291. IPEA, 1993.

CACCIAMALI, M. C. Setor informal urbano e formas de participação na produção. Tese de Doutorado, USP, 1983.

CACCIAMALI, M. C. Comentários ao artigo Setor Informal: do excedente estrutural à esco- 
Iha individual. Marcos Interpretativos e Alternativas de Política, de Carlos Alberto Ramos. Econômica: revista da Pós-Graduação em Economia da Universidade Federal Fluminense. 2007; 9(1):145.

CIMOLI, M; PRIMI, A.; PUGNO, M. A low-growth model: Informality as a structural constraint. Cepal Review, v. 88, p. 85, 2006.

DOERINGER, P. B.; MICHAEL, J. P. Internal Labor Markets and Manpower, Analysis. Lexington, MA: Heath, 1981.

FEIJÓ, C. A.; RAMOS, R. L. O. Contabilidade social: a nova referência das contas nacionais do Brasil. Campus, 2008.

FIELDS, G. S. Segmented labor market models in developing countries. 2009. Disponível em: Cornell University, ILR School site <http://digitalcommons.ilr.cornell.edu/articles/162/>.

GÜNTHER, I.; LAUNOV, A. Competitive and Segmented Informal Labor Markets. Forschungsinstitut zur Zukunft der Arbeit, Institute for the Study of Labor, September 2006, Discussion paper series, IZA DP No. 2349. Disponível em <http://ftp.iza.org/dp2349. $\mathrm{pdf}>$.

HALLAK NETO, J.; NAMIR, K.; KOZOVITS, L. Sector and Informal Employment in Brazil. Paper Prepared for the Special IARIW-SAIM Conference on "Measuring the Informal Economy in Developing Countries", Kathmandu, Nepal, September 23-26, 2009.

HALLAK NETO, J.; NAMIR, K.; KOZOVITS, L. Setor e emprego informal no Brasil: análise dos resultados da nova série do sistema de contas nacionais-2000/07. Revista Economia e Sociedade, v. 44, 2012.

HARRIS, J. R.; TODARO, M. P. Migration, unemployment and development: a two-sector analysis. The American Economic Review, p. 126-142, 1970.

HEINTZ, J.; POSES, D. Revisiting Informal Employment And Segmentation In The South African Labour Market. South African Journal of Economics, v. 76, i. 1, p. 26-44, March 2008.

HIRATA, G. I.; MACHADO, A. F. Conceito de informalidade/formalidade e uma proposta de tipologia. Econômica: revista da Pós-Graduação em Economia da Universidade Federal Fluminense, 2008, v.10, n.1, p. 123-143.

HUSSMANNS, R. Statistical defnition of informal employment: guidelines endorsed by the Seventeenth International Conference of Labour Statisticians (2003). In: Meeting of the expert group on informal sector statistics (delhi group), 7th, 2004. Anais..., 2004. p. 2-4.

IBGE - INSTITUTO BRASILEIRO DE GEOGRAFIA E ESTATÍSTICA. Sistema de contas nacionais Brasil - referência 2000 - Nota metodológica n. 8: setores institucionais. IBGE. Rio de Janeiro, 2008a.

IBGE - INSTITUTO BRASILEIRO DE GEOGRAFIA E ESTATÍSTICA. Sistema de contas nacionais Brasil - referência 2000 - Nota metodológica n. 23: setores institucionais. IBGE. Rio de Janeiro, $2008 b$.

IBGE - INSTITUTO BRASILEIRO DE GEOGRAFIA E ESTATÍSTICA. Sistema de contas nacionais Brasil - séries relatórios metodológicos, n. 24. Rio de Janeiro: IBGE, 2008c.

IBGE - INSTITUTO BRASILEIRO DE GEOGRAFIA E ESTATÍSTICA. Sistema de contas nacionais Brasil - Nota metodológica n. 13: atividade financeira. Rio de Janeiro: IBGE, 2010. 
KREIN, J. D.; PRONI, M. W. Economia informal: aspectos conceituais e teóricos. Série Trabalho Decente no Brasil; Documento de trabalho n.4. OIT. Escritório da OIT no Brasil. Brasília, 2010 v. 1.

KUPFER, D.; ROCHA, F. Productividad y heterogeneidade estructural en la indústria brasileña. In: CIMOLI, M. (Org.). Structural heterogeneity, technological asymmetries and growth in Latin America. 2005.

LAVOIE, M. Post-Keynesian Economics: New Foundations. Cheltenham, Edward Elgar, 2014.

LEWIS, W. A. Economic development with unlimited supplies of labour. The manchester school, v. 22, n. 2, p. 139-191, 1954.

OCAMPO, J. A.; RADA, C.; TAYLOR, L; Growth and Policy in Developing Countries: A Structuralist Approach. Columbia University Press, 2009.

ORGANIZAÇÃO INTERNACIONAL DO TRABALHO - OIT. Employment, incomes and equality: a strategic for increasing productive employment in Kenya. Geneva: ILO, 1972.

ORGANIZAÇÃO INTERNACIONAL DO TRABALHO - OIT. Decent work and the informal economy. Geneva: ILO, 2002.

PROGRAMA REGIONAL DEL EMPLEO PARA AMÉRICA LATINA Y EL PREALC. Sector informal: funcionamento y politicas. Santiago de Chile: OIT, 1978.

RADA, C. Stagnation or transformation of a dual economy through endogenous productivity growth. Cambridge Journal of Economics, v. 31, n. 5, p. 711-740, 2007.

RAMOS, L. A evolução da informalidade no Brasil metropolitano: 1991-2001. Texto para Discussão, 914. IPEA, 2002.

SOARES, F. V. Do informal workers Queue for formal jobs in Brazil? Texto para Discussão, 1.021. IPEA, 2004.

SHAPIRO, C.; STIGLITZ, J. E. Equilibrium Unemployment as a Worker Discipline Device. American Economic Review, 1984.

STIGLITZ, J. E. Equilibrium Wage Distributions. The Economic Journal, 1985, 95, p. 595-618.

TOKMAN, V. E.; SOUZA, P. R. El sector informal urbano en America Latina. Revista Internacional del Trabajo, v. 94, n. 3, 1976.

TOKMAN, V. E.; SOUZA, P. R. Distribución del ingresso, pobreza y empleo en areas urbanas. El Trimestre Economico, jan./abr. 1978. ULYSSEA, G. Informalidade no mercado de trabalho brasileiro: uma resenha da literatura. Texto para Discussão n. 1070. Brasília: Ipea, 2005.

\section{Sobre os autores}

Claudio RobertoAmitrano-claudio.amitrano@ipea.gov.br

Técnico de Planejamento e Pesquisa do Instituto de Pesquisa Econômica Aplicada (Ipea), Brasília/DF.

Gabriel Coelho Squeff - gabriel.squeff@ipea.gov.br

Técnico de Planejamento e Pesquisa do Instituto de Pesquisa Econômica Aplicada (Ipea), Brasília/DF.

\section{Sobre o artigo}

Recebido em 27 de julho de 2015. Aprovado em 09 de agosto de 2016. 